\title{
Performance of temperature and radiation index models for point-scale snow water equivalent (SWE) simulations in the Moroccan High Atlas Mountains
}

\author{
H. Bouamri, A. Boudhar, S. Gascoin \& C. Kinnard
}

To cite this article: H. Bouamri, A. Boudhar, S. Gascoin \& C. Kinnard (2018): Performance of temperature and radiation index models for point-scale snow water equivalent (SWE) simulations in the Moroccan High Atlas Mountains, Hydrological Sciences Journal, DOI: 10.1080/02626667.2018.1520391

To link to this article: https://doi.org/10.1080/02626667.2018.1520391

Accepted author version posted online: 10

Sep 2018.

Published online: 26 Oct 2018.

Submit your article to this journal $\pi$

Џ Article views: 15

View Crossmark data $[7$ 


\title{
Performance of temperature and radiation index models for point-scale snow water equivalent (SWE) simulations in the Moroccan High Atlas Mountains
}

\author{
H. Bouamria, A. Boudhar ${ }^{\mathrm{a}}$, S. Gascoin ${ }^{\mathrm{b}}$ and C. Kinnard ${ }^{\mathrm{c}}$ \\ aÉquipe de recherche Gestion et Valorisation des Ressources en Eau et Télédétection, Faculté des Sciences et Techniques, Université Sultan \\ Moulay Slimane, Béni-Mellal, Morocco; ${ }^{b}$ CESBIO, Université de Toulouse CNES/CNRS/IRD/UPS, Toulouse, France; 'Département des Sciences \\ de I'Environnement, Université du Québec à Trois-Rivières, Trois-Rivières, Canada
}

\section{ABSTRACT}

Four models of increasing complexity were tested and compared to simulate snow water equivalent at the local scale in the Moroccan High Atlas range. A classical temperature index model (TI) and three enhanced temperature index models that respectively include the potential clear-sky direct radiation ( $\mathrm{HTI})$, the incoming solar radiation (ETI-A) and net solar radiation (ETI-B), were subjected to annual and multi-annual calibration and cross-validated over the period 2003-2010. When calibrated yearly, the ETI models could be better transferred to other years, whereas all models, including the simple TI model, showed good transferability when calibrated over a longer period that includes inter-annual climate variability. No strong and recurrent relationships emerged between yearly calibrated model parameters and annual climate conditions. However, strong parameter compensation was observed for the enhanced models, which can be explained partly by the collinearity of air temperature and solar radiation causing equifinality of model parameters.
ARTICLE HISTORY

Received 5 March 2018

Accepted 7 August 2018

EDITOR

A. Castellarin

\section{ASSOCIATE EDITOR}

G. Thirel

\section{KEYWORDS}

snow water equivalent; temperature index model; enhanced degree-day models; semi-arid climate; High Atlas; Morocco

\section{Introduction}

In arid and semi-arid regions, snowfall and rainfall in mountainous areas constitute an important source of water for domestic, industrial and agricultural use (Viviroli and Weingartner 2004, Bales et al. 2006). In such contexts, hydrological processes are extremely heterogeneous due to the marked temporal variability in hydro-climatic conditions combined with the strong topographic gradients and diverse land cover distributions (Cudennec et al. 2007, De Jong et al. 2008, Muñoz et al. 2012, Fayad et al. 2017). According to model projections, future climate conditions in these areas will strongly affect water availability due to a reduction of snowfall and rainfall amounts, and snowpack depletion driven mainly by warmer temperatures (Barnett et al. 2005, López-Moreno et al. 2009, 2017).

The Atlas Mountains of Morocco, considered to be a water tower for the surrounding arid plains, produce a large proportion of the water supply for agriculture activities, dam storage, hydropower production and aquifer recharge (Chehbouni et al. 2008, Jarlan et al. 2015). In winter and spring, a significant part of the precipitation is stored temporarily as snow, which controls river runoff during the snowmelt period (Boudhar et al. 2009a). As in other semi-arid mountain ranges of the world, the snow cover is highly variable at annual and inter-annual time scales (Marchane et al. 2015, Boudhar et al. 2016), which greatly affects the storage capacity of catchments and the hydrological contribution of snowmelt to total runoff. In the Tensift River basin, where the present study was conducted, snowmelt was found to contribute $15-50 \%$ of the annual river discharge in the main headwater catchments, this proportion varying between hydrological years and among catchments (Boudhar et al. 2009a).

In this context, estimating snow accumulation and snowmelt contribution to runoff is highly relevant for water management purposes. The traditional approaches used to calculate snowmelt range from simple empirical models (e.g. Kustas and Rango 1994, Hock 2003) to more sophisticated, physically-based models that resolve the full energy balance at the snow surface (Tarboton and Luce 1996, Liston and Elder 2006, DeWalle and Rango 2008, Herrero and Polo 2016). These latter models describe all major processes controlling snowpack evolution and quantify melt as the residual of the energy balance equation. They require a large amount of input meteorological variables, usually at an hourly time step, which are typically either not available or scarce in high mountain catchments. In such conditions, conceptual models with lower data requirements are preferred. 
Several previous studies have shown that degree-day models, which depend solely on air temperature, provide satisfactory estimates of melting rates in various locations and climates (Singh and Jain 2003, Schneider et al. 2007, Boudhar et al. 2016, Fassnacht et al. 2017). The strong correlation between air temperature and snowmelt can be explained by the dependence of the sensible heat and atmospheric long-wave radiation fluxes to air temperature (Ohumura 2001, Hock 2003). Despite their simplicity, these models generally perform well both at the point scale and within distributed or lumped hydrological models (Binley et al. 1997, Li and Williams 2008, Abudu et al. 2012, Kampf and Richer 2014, Tayal Senzeba et al. 2015, Hublart et al. 2016). Even so, melt factors in degree-day models can vary significantly in time due changes in energy flux partitioning between the snow surface and the atmosphere, and spatially in response to topography and land cover (Fassnacht et al. 2017). The net solar radiation generally contributes between 50 and $90 \%$ of the energy available for snowmelt (e.g. Willis et al. 2002, Mazurkiewicz et al. 2008). As such, air temperature and solar radiation have been the two main meteorological variables used to predict snowmelt rates (Brubaker et al. 1996, Richard and Gratton 2001, Hock 2003). Many attempts have been made to improve the physical foundation of empirical melt models and enhance their performance by incorporating additional predictive variables such as wind speed, vapour pressure or radiation (e.g. Zuzel and Cox 1975, Willis et al. 1991, Kustas and Rango 1994, Rango and Martinec 1995, Franz et al. 2010). These models have been referred to broadly as "enhanced" temperature index models and represent a trade-off between simple degree-day models and explicit energy balance models (Hock 2003). Most enhanced melt models include a solar radiation term, either in the form of potential clear-sky direct (Hock 1999), global (Kustas and Rango 1994) or net (Pellicciotti et al. 2005) solar radiation. These enhanced models have often been found to outperform classical degree-day methods on a daily or even hourly basis (Hock 2005, Homan et al. 2011, Raleigh and Lundquist 2012).

When used within hydrological models, parameters of empirical melt models are often calibrated at the same time as the hydrological parameters, which can give rise to equifinality problems and hamper the transferability of model parameters (Beven 1993, 2006). This motivates the use of additional data, such as measured snow depth, to calibrate snowmelt parameters independently from hydrological parameters. There are, however, indications that the parameters of simple temperature index models can depend strongly on the climatic conditions of the calibration period, calling into question their transferability over time (Gabbi et al. 2014, He et al. 2014). This is in fact to be expected from simple melt models with few parameters, which do not fully account for inter-annual variations in energy flux partitioning between the atmosphere and the snow surface. The problem of climate dependency of model parameters is likely to be more acute when the period of data available for calibration is short, which can require recalibration of the models for individual subperiods (Huss et al. 2009). The formulation of "enhanced" melt models seeks to address this shortcoming partly by considering additional processes while maintaining a simple model structure and a low data requirement. The increased physical realism of enhanced models may help to alleviate the climate dependency of the calibrated parameters, however at the cost of increased model complexity, i.e. the number of parameters to be calibrated.

In contrast to calibrated empirical melt models, physically-based models with minimal or no calibration have been found to be more transferable over time and space, with only a small decrease in model performance (Carenzo et al. 2009). These models are therefore less dependent on climate conditions and can be more reliably extrapolated over time (Gabbi et al. 2014). However, due to their more complicated structure and higher data requirements, these models are more difficult to apply within distributed hydrological models, and hence are less often used for this purpose.

The application of empirical melt models in semi-arid regions is further complicated by snow sublimation. Several studies have shown that sublimation can considerably reduce the energy available for melt in such regions (e.g. Hock 2003, Froyland 2013, Gascoin et al. 2013, MacDonell et al. 2013, Herrero and Polo 2016), which can complicate the melt-temperature relationship and the calibration of simple empirical melt models. The semi-arid climate conditions of the Atlas Mountains favour snow sublimation, which can represent a non-negligible fraction of annual snow ablation. Based on energy balance calculations in earlier studies, the sublimation ratio (total sublimation/total ablation) was found to be as high as $44 \%$ on the south slopes of the Atlas (Schulz and de Jong 2004), while on the north slopes this ratio was found to be lower, varying between 7 and 20\% depending on the year (Boudhar et al. 2016). This large difference in sublimation ratios is consistent with the fact that the northern, windward side of the Atlas intercepts moist air masses from the Atlantic Ocean, while the leeward side is relatively more depleted in moisture and more arid (Knippertz et al. 2003, Schulz and de Jong 2004).

There have been few studies that have looked at the respective performance of empirical models in semiarid mountainous areas, and explicitly explored the issues of coefficient transferability over time and their dependency on climate conditions. These issues are 
important in order to guide model calibration practices in the context of limited data availability, which often plagues remote mountain sites such as the Atlas. Such models could become particularly useful in the operational framework of water management, given the lack of weather data in the High Atlas to run energy-balance models. Therefore, the aim of the present study is twofold: (1) to evaluate the performance of four simplified approaches, ranging from a simple degree-day method to enhanced degree-day methods that include the incoming radiation and albedo, to simulate snow water equivalent (SWE) at the station scale over the period 2003-2010 in the Moroccan High Atlas range; and (2) to assess the models' transferability over time and the climate dependency of the model parameters, using different calibration/validation strategies.

\section{Study area and data}

This study was carried out in the High Atlas Mountain range, located in central Morocco (Fig. 1). This range reaches its maximum elevation at the summit of Jbel Toubkal, the highest mountain of North Africa, at $4174 \mathrm{~m}$ a.s.l.

The area has a semi-arid climate with two contrasted seasons: a wet season from October to May and a dry season from June to September. Because of the orographic effect, the High Atlas Mountains receive more precipitation than adjacent lowlands, with approximately $50 \%$ falling as snow (Boudhar et al. 2016). Annual cumulative precipitation can exceed $800 \mathrm{~mm}$ at high elevations, due to orographic uplift of cold and moist air masses from the North Atlantic Ocean. Precipitation falls mostly as snow above $1400 \mathrm{~m}$ a.s.l. during winter and spring, generally from November to early May (Boudhar et al. 2009a). The monthly precipitation climatology as recorded between 1988 and 2010 at the Club Alpin Français (CAF) manual weather station, located $3 \mathrm{~km}$ from the study site at $2600 \mathrm{~m}$ a.s.l. is shown in Figure 2 (a); the median monthly precipitation was lowest in July $(7 \mathrm{~mm})$ and reached a maximum of $69 \mathrm{~mm}$ in March. Higher precipitation generally occurred between January and April, but with marked inter-annual variability, especially during the season transitions (January and March), with inter-quartile ranges of 102 and $71 \mathrm{~mm}$, respectively. In contrast, precipitation is scarce and less variable from July until early September. According to a long-term analysis of snow-covered area using remote sensing data (Marchane et al. 2015), snow cover dynamics in the High Atlas mountains is strongly heterogeneous and exhibits marked annual, seasonal and even weekly variability in response to meteorological variability.

The meteorological data used in this study were recorded every $30 \mathrm{~min}$ by the automatic weather station (AWS) at Oukaimeden-SM, in operation since 2003. The station is located at an altitude of $3200 \mathrm{~m}$ a.s.l., on the northern side of the High Atlas in the headwaters of the Rheraya sub-catchment and about $70 \mathrm{~km}$ south of Marrakech city (Fig. 1). Recorded data include precipitation, air temperature, snow depth, albedo, shortwave

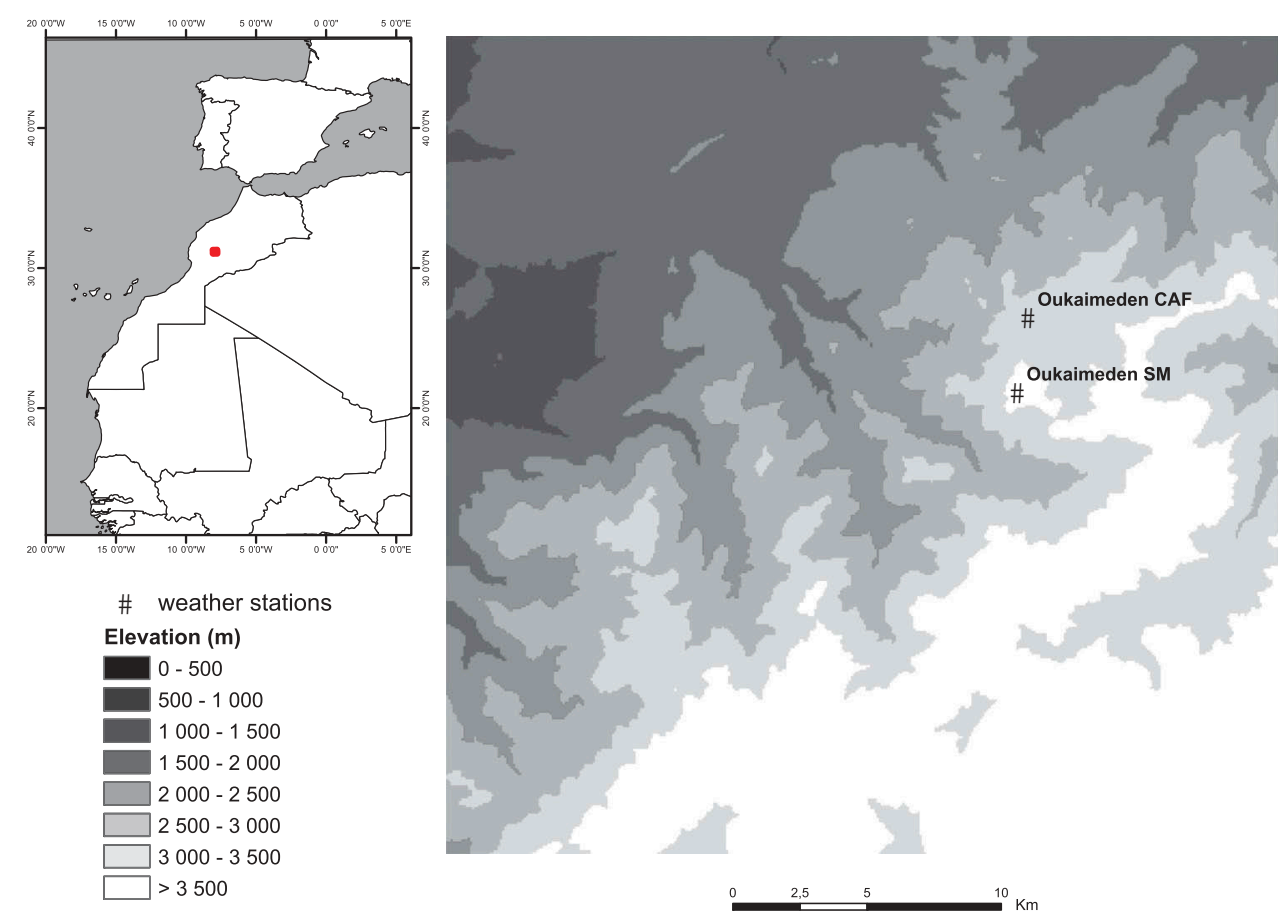

Figure 1. Location of the High Atlas mountain range and Oukaimeden CAF and Oukaimeden-SM weather stations. 
(a)

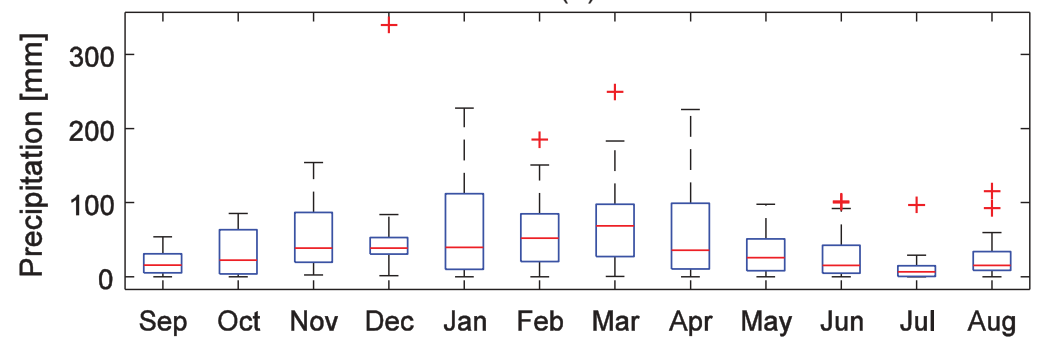

(b)

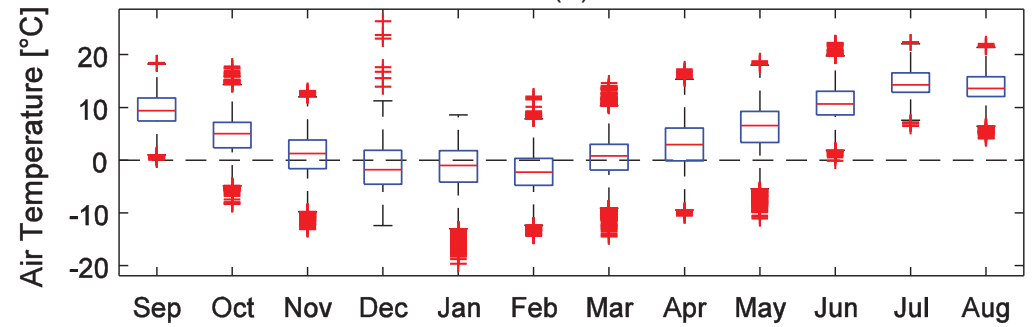

Figure 2. Precipitation and air temperature climatology at the study site (see Fig. 1 for locations). (a) Monthly distribution of precipitation (snow and rainfall) recorded between 1988 and 2010 at the Oukaimeden CAF station (2600 m a.s.l.). (b) Monthly distribution of air temperature recorded between 2003 and 2009 at the Oukaimeden-SM automatic weather station (3200 m a.s.I.).

radiation and wind speed. Detailed information on the meteorological instrumentation is given by Boudhar et al. (2016). The mean annual temperature registered at the Oukaimeden-SM AWS between 2003 and 2009 was $11^{\circ} \mathrm{C}$, while daily temperature could reach $-20^{\circ} \mathrm{C}$ in winter and $25^{\circ} \mathrm{C}$ in summer (Fig. 2(b)).

Continuous snow depth was measured by a sonic distance sensor. The 2006/07 and 2008/09 years were excluded from the analysis due to unreliable snow data, leaving a total of five hydrological years for analysis. The weather station has an unheated tipping-bucket raingauge, which yields unreliable snow precipitation data in winter and therefore was not used in this study. While the CAF station has more reliable manual observations of precipitation (see Fig. 2(a)), it is located $600 \mathrm{~m}$ lower than Oukaimeden-SM and could not be confidently extrapolated to the study site. Radiation measurements also suffer from a large data gap before 2009 due to a sensor change. As a result, parameterizations for the global radiation and snow albedo were developed and calibrated in 2009/10 and then applied to the whole period, as described in the Methods section.

\section{Methods}

\section{Snow mass balance}

The snowpack mass balance can be expressed by the following equation (e.g. King et al. 2008, Herrero et al. 2009):

$$
\mathrm{dSWE} / \mathrm{d} t=P-M-E \pm W
$$

where $\mathrm{dSWE} / \mathrm{d} t$ is the change in snow mass per unit time (d), $P$ is the snow precipitation rate (accumulation), $E$ is the sum of sublimation and evaporation rates at the surface, $M$ is the melt rate, and $W$ is an advective wind transport term, which can be positive (deposition) or negative (erosion).

As continuous SWE measurements are not available at this site, the SWE records previously estimated by Boudhar (2009b) were used in this study. Boudhar (2009b) converted the snow depth records to SWE using the snow density parameterization of Verseghy (1991):

$$
\begin{aligned}
\rho_{s}(t+\Delta t)= & \left(\rho_{s}(t)-\rho_{\max }\right) \times \exp \left\{\tau_{f} \Delta t / \tau\right\} \\
& +\rho_{\max }
\end{aligned}
$$

where $\rho_{s}$ is the snow density, $\rho_{\max }$ is the maximum snow density, set to $300 \mathrm{~kg} \mathrm{~m}^{-3}, \Delta t=1 \mathrm{~d}$, and $\tau_{f} / \tau$ is the characteristic time $\left(0.24 / 4800 \mathrm{~s}^{-1}\right)$. The fresh snow density $\left(\rho_{\text {new }}\right.$, in $\mathrm{kg} \mathrm{m}^{-3}$ ) was calculated by (Pomeroy et al. 1998):

$$
\rho_{\text {new }}=67.92+51.25 \times \exp \left\{T_{a} / 2.59\right\}
$$

where $T_{a}$ is air temperature in ${ }^{\circ} \mathrm{C}$. A mean snowpack density, $\overline{\rho_{s}}$, was calculated at each time step as the average of the old $\left(\rho_{s}\right)$ and new snow $\left(\rho_{\text {new }}\right)$ densities weighted by their respective depths. A $0.5 \mathrm{~kg} \mathrm{~m}^{-3}$ ${ }^{\circ} \mathrm{C}^{-1} \mathrm{~h}^{-1}$ density increase was also applied during melting conditions $\left(T_{a}>0\right)$ to include the effect of meltwater refreezing on snowpack density. If the resulting density value rises above $\rho_{\max }$, Equation (2) is not 
applied and the density is limited to a maximum of $450 \mathrm{~kg} \mathrm{~m}^{-3}$, based on observations. The density can still decrease afterward following fresh snowfall. Snow depths $(\mathrm{mm})$ were converted to SWE $(\mathrm{mm})$ at each half-hour time step using:

$$
\mathrm{SWE}=\overline{\rho_{s}} / \rho_{w} \times \text { snow depth }
$$

where $\rho_{w}$ is the density of water $\left(1000 \mathrm{~kg} \mathrm{~m}^{-3}\right)$. The parameterization was previously calibrated using in situ snow density measurements at the Oukaimeden-SM AWS site and found to give fair results with $R^{2}=0.72$ and RMSE $=40 \mathrm{~mm}$ (Boudhar 2009b). Daily estimated SWE averages were further used in this study and are referred to as "estimated SWE" in the remainder of the text.

As reliable precipitation data were not available at this study site, and also because this study focuses on the performance of different snowmelt calculations for simulating SWE and not the simulation of accumulation, the observed snow accumulation was used to drive the models instead of measured precipitation. This means that on days with observed accumulation (dSWE/d $t>$ thres), precipitation $(P)$ is inferred from Equation (1) using the observed accumulation, the calculated melt $(M)$, if any, and sublimation $(S)$ for that day. A detection threshold (thres) of $1 \mathrm{~mm}$ w.e. $(\sim 1 \mathrm{~cm}$ snow depth), which corresponds to the measurement uncertainty of the ultrasonic snow depth sensor, was used to discriminate accumulation from measurement errors. Using the observed accumulation also effectively prevents introducing model uncertainties due to gauge undercatch errors, which typically plague snowfall measurements in mountainous environments (Fassnacht 2004, Rasmussen et al. 2012), and errors due to rain/ snow discrimination, ultimately avoiding the problem of the melt algorithms compensating these errors during calibration. The melt models were calibrated on the estimated SWE records rather than on ablation estimated from daily negative SWE changes, in part because day-to-day changes in measured snow depth from ultrasonic gauges can be noisy, and also because surface lowering can lag behind melting (Pellicciotti et al. 2005). As winter precipitation data were not used, any rainfall effects on snowmelt were not considered in the simple melt models used here, and this may represent a potential source of error in melt calculations. Rain-onsnow events are complicated processes that would require the application of a physically-based, multilayered snow model (e.g. Würzer et al. 2016), which is beyond the scope of this study.

To take into account sublimation losses, a constant, mean daily sublimation rate $(E)$, previously calculated via an energy balance model at the Oukaimeden-SM AWS site (Boudhar et al. 2016) has been used in the model formulation. A distinct mean daily sublimation rate was used for each hydrological year, as reported by Boudhar et al. (2016). The use of a constant sublimation rate removes the positive bias in melt that would arise if sublimation losses were not accounted for. However, variations in the daily sublimation rate may still be a source of error in the simulated daily melt rates. The influence of mean sublimation rate on yearly calibrated model coefficients is investigated later in this paper.

\section{Filtering of wind erosion events}

Snow redistribution by wind ( $W$ in Equation (1)) can be significant in mountainous terrain (Liston et al. 2007, Gascoin et al. 2013). The probability of blowing snow increases with wind speed and decreases with snow age and air temperature (Li and Pomeroy 1997). Since the models were forced with measured snow accumulation, any snow deposited by wind was already accounted for. However, as the simple snowmelt routines do not account for snow erosion, any such events would introduce errors in the models and exaggerate the simulated melt rates. While the estimated SWE records at the Oukaimeden-SM AWS site did not appear to be particularly affected by snow transport during the years studied, even small erosion events during certain years could strongly bias the calibration of the melt models. As our objective is to compare model performance and obtain representative melt parameters, a filtering step was introduced to identify potential wind erosion events and exclude them from the calibration of the melt equations. Parameterizations for blowing snow probability such as the one proposed by Li and Pomeroy (1997) were developed from, and for, hourly data and are thus not directly applicable to daily data. The filtering step used instead identifies anomalous rises in ablation rate followed by an equally rapid decline over a one or twoday period. The change in ablation rate over time was calculated as the second differential of the estimated SWE record. A threshold of $15 \mathrm{~mm} \mathrm{~d}^{-1}$, called the wind factor (WF), was used to discriminate "anomalous" rises in ablation rates from normal conditions. This means than if the ablation rate rose and fell by more than $15 \mathrm{~mm} \mathrm{~d}^{-1}$ over a one- or two-day period the ablation event was deemed highly probably to have been caused by wind erosion. In addition, because blowing snow probability decreases sharply over melting snow, only events with negative air temperatures were retained. This also decreases the chance that the filtered ablation events were caused by a rain event. The wind factor, WF, must be specified based on visual interpretation of the $\mathrm{d}^{2} S W E / \mathrm{d} t^{2}$ plots, as shown in 
(a)

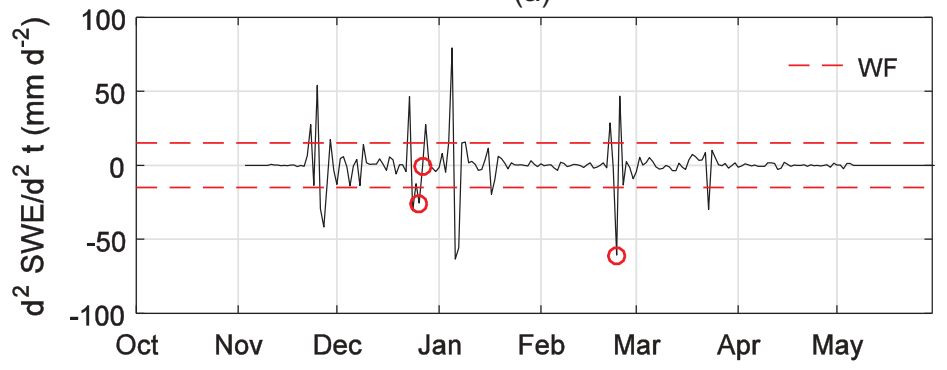

(b)

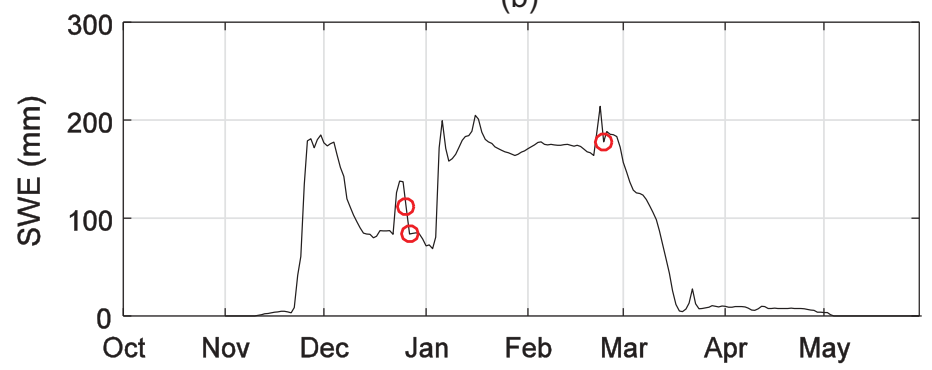

Figure 3. Filtering of wind erosion events from the daily SWE measured in 2007/08. (a) Anomalous increases in ablation rate are identified as those days that successively cross the lower (-WF) and upper (+WF) wind factor threshold within a 1- or 2-day period (circles), which was determined from the second derivation of SWE $\left(\mathrm{d}^{2} \mathrm{SWE} / \mathrm{d} t^{2}\right) d^{2} \mathrm{SWE} / \mathrm{d} t^{2}$. (b) Detected erosion events superimposed on the SWE record.

Figure 3(a). Days that vary below $-W F$ and above +WF within one or two days are flagged as probable wind erosion events. The detected events correspond well with those that were visually identified on the SWE record (Fig. 3(b)). Sixteen events (days) were detected, which represent $2 \%$ of snow days over the 5 year period. Using a nonparametric Mann-Whitney $U$ (rank sum) test we found that the wind speed was significantly higher, the snow age significantly younger, and the air temperature significantly lower for the 16 erosion events compared to the remaining snow days, while no significant difference was found for relative humidity $(p<0.05)$. This increases our confidence that these ablation events resulted from wind erosion. Melt was not simulated during these events and the estimated SWE was used during the calibration of the melt equations.

It is worth noting that using the observed accumulation and filtering out wind erosion events will yield the best SWE simulations possible by the melt models. Our goal here is to obtain the best melt model parameters, whose calibration is the least affected by precipitation data quality and/or any snow erosion. Applying these parameters within distributed or lumped hydrological models will thus ensure that melt is correctly simulated, understanding that errors in precipitation data and/or wind redistribution would further affect the spatial simulation of snow cover and result in reduced model performance compared to the point-scale applications described here.

\section{Snowmelt models}

Four models of increasing complexity were used to simulate snowmelt at the Oukaimeden-SM weather station site. Model formulation ranged from the simple, classical degree-day method to different "enhanced" degree-day methods. Each model is outlined below.

\section{Classical temperature index (TI) melt model}

Temperature index models or so-called degree-day models are considered the most classical method for melt modelling due to the widespread availability of air temperature data and their computational simplicity. These models also perform generally well, being generally classified amongst the most efficient models used for melt modelling (Hock 2003). The model has a single coefficient or factor of proportionality, called the "degree-day factor" (DDF, in $\left.\mathrm{mm}{ }^{\circ} \mathrm{C}^{-1} \mathrm{~d}^{-1}\right)$ :

$$
M=\left\{\begin{array}{cr}
\mathrm{DDF} \times T_{\mathrm{a}} & T_{\mathrm{a}}>T_{\mathrm{T}} \\
0 & T_{\mathrm{a}} \leq T_{\mathrm{T}}
\end{array}\right.
$$


where $M$ is the melt rate $\left(\mathrm{mm} \mathrm{d}^{-1}\right), T_{\mathrm{a}}$ is daily mean air temperature $\left({ }^{\circ} \mathrm{C}\right)$ and $T_{\mathrm{T}}$ is a threshold temperature beyond which snowmelt is supposed to occur, fixed at $0^{\circ} \mathrm{C}$ in this study.

\section{Hock's temperature index melt model (HTI)}

To enhance the classical model (TI), the potential incoming direct solar radiation $\left(I_{\text {pot }}\right)$ for clear-sky conditions was added as proposed by Hock (1999). In this structure, the melt factor (MF) varies seasonally according to $I_{\text {pot }}$

$$
M=\left\{\begin{array}{cr}
\left(\mathrm{MF}+\mathrm{RF} \times I_{\mathrm{pot}}\right) T_{\mathrm{a}} & T_{\mathrm{a}}>T_{\mathrm{T}} \\
0 & T_{\mathrm{a}} \leq T_{\mathrm{T}}
\end{array}\right.
$$

where $M$ is daily melt $\left(\mathrm{mm} \mathrm{d}^{-1}\right), I_{\text {pot }}$ is the potential clear-sky incoming direct solar radiation $\left(\mathrm{W} \mathrm{m}^{-2}\right)$, and MF and RF are two empirical coefficients, respectively the melt factor and radiation factor (expressed in $\mathrm{mm} \mathrm{d}^{-1}{ }^{\circ} \mathrm{C}^{-1}$ and $\mathrm{m}^{2} \mathrm{~mm} \mathrm{~W}^{-1} \mathrm{~d}^{-1}{ }^{\circ} \mathrm{C}^{-1}$, respectively).

The potential, clear-sky direct solar radiation is calculated as a function of solar geometry, topography and a constant vertical atmospheric transmissivity (Hock and Noetzli 1997, Hock 1999):

$$
I_{\text {pot }}=I_{0}\left(R_{m} / R\right) \times \psi a^{\left(P / P_{0} \cos Z\right)} \times \cos \theta
$$

where $I_{0}$ is the solar constant $\left(1368 \mathrm{~W} \mathrm{~m}^{-2}\right), R_{m}$ and $R$ are the mean and actual Sun-Earth distance, $\psi a$ is the vertical clear-sky atmospheric transmissivity (-), $P$ is the atmospheric pressure in $\mathrm{Pa}$ and $P_{0}$ is standard atmospheric pressure (101 $325 \mathrm{~Pa}), Z$ is the solar zenith angle, and $\theta$ is the incidence angle of the Sun on the surface. The ratio $P / P_{0}$ accounts for the effect of altitude (lower air pressure yields higher solar radiation) and the introduction of $\cos Z$ in the exponent expresses the variation of the path length with Sun altitude (Hock 1999). The vertical clear-sky transmissivity, $\psi a$, was calibrated by minimizing the root mean square error (RMSE) between $I_{\text {pot }}$ and the global radiation measured on clear days, during the year 2009/10 with reliable measurements. "Clear" days were classified as those having a mean daily radiation value larger than $80 \%$ of the radiation at the top of the atmosphere (TOA). A constant direct (diffuse) fraction of solar radiation of $85 \%$ (15\%) was assumed for the selected clear days (e.g. Hock and Holmgren 2005). An optimal $\psi a$ value of 0.75 was found $\left(\right.$ RMSE $=14.9 \mathrm{~W} \mathrm{~m}^{-2}$, NSE $\left.=0.92\right)$.

\section{Enhanced temperature index (ETI-A) melt model}

The enhanced temperature index melt model includes global radiation (incoming shortwave radiation), which is an important energy source for melt (Hock 2005).
This model separates melting induced by solar radiation from that induced by temperature-dependent energy fluxes (Pellicciotti et al. 2005):

$$
M=\left\{\begin{array}{r}
\mathrm{TF} \times T_{\mathrm{a}}+\mathrm{SRF}_{\mathrm{in}} \times I T_{\mathrm{a}}>T_{\mathrm{T}} \\
0 \quad T_{\mathrm{a}} \leq T_{\mathrm{T}}
\end{array}\right.
$$

where $I$ is incoming shortwave radiation $\left(\mathrm{W} \mathrm{m}^{-2}\right)$, TF is the temperature factor $\left(\mathrm{mm} \mathrm{d}^{-1}{ }^{\circ} \mathrm{C}^{-1}\right)$ and $S R F_{\text {in }}$ is the radiation factor $\left(\mathrm{m}^{2} \mathrm{~mm} \mathrm{~W}^{-1} \mathrm{~d}^{-1}\right)$. The index "in" stands for incoming shortwave radiation, to differentiate from the ETI-B model, described next.

\section{Enhanced temperature index (ETI-B) melt model}

The ETI-B model structure is similar to ETI-A, but considers the net shortwave radiation instead of only the incoming shortwave radiation. This model, proposed by Pellicciotti et al. (2005), is considered the most physically-based of all the aforementioned melt models, as it includes the variability in snow albedo:

$$
M=\left\{\begin{array}{cr}
T F \times T_{\mathrm{a}}+\mathrm{SRF}_{\text {net }}(1-\alpha) I & T_{\mathrm{a}}>T_{\mathrm{T}} \\
0 & T_{\mathrm{a}} \leq T_{\mathrm{T}}
\end{array}\right.
$$

where $\alpha$ is albedo and $I$ the incoming shortwave radiation $\left(\mathrm{W} \mathrm{m}^{-2}\right)$, and TF and $S R F_{\text {net }}$ are two empirical coefficients, respectively the temperature factor and net shortwave radiation factor (expressed in $\mathrm{mm} \mathrm{d}^{-1}{ }^{\circ} \mathrm{C}^{-1}$ and $\mathrm{m}^{2} \mathrm{~mm} \mathrm{~W}^{-1} \mathrm{~d}^{-1}$ ).

\section{Forcing variables and model calibration}

As previously mentioned, some meteorological variables were not available or limited at the Oukaimeden-SM AWS and were thus parameterized. These parameterizations are detailed below.

\section{Global radiation}

The temperature index models based on incoming and net solar radiation (Equations (8) and (9)) require reliable measurements of global radiation, which in our case were only available for the 2009/10 season. Hence parameterizations for global radiation and albedo (see next section) were sought in order to apply the ETI-A and -B models to the full period. Global radiation was parameterized using the calculated potential clear-sky direct solar radiation and an $R$ ratio:

$$
R=G / I_{\text {pot }}
$$

where $R$ is the ratio between the global radiation $(G)$ and the potential clear-sky direct solar radiation $\left(I_{\mathrm{pot}}\right)$, and accounts for the effects of clouds and diffuse radiation (Hock 1999, Hock and Holmgren 2005). If measured 
global radiation exceeds the calculated direct radiation $(R>1)$, the difference indicates the amount of diffuse radiation. Conversely, measured global radiation less than calculated $(R<1)$ is caused by cloud cover. Atmospheric conditions, especially cloud cover, surrounding topography and the Sun position are the major parameters influencing the $R$ ratio. As variations in $R$ are predominantly due to clouds the $R$ ratio is akin to, but different from, the "cloud factor" used in other studies (e.g. Pellicciotti et al. 2011). In our case, since the clear-sky transmissivity is assumed constant, the $R$ ratio also reflects variations in air humidity and aerosol concentration.

Since reliable global radiation measurements were only available for one year, and in order to use modelling approaches as simple as possible, methods relying on commonly observed data (i.e. temperature, humidity and precipitation) were used to parameterize unmeasured variables such as the $R$ ratio and albedo. A parameterization of the $R$ ratio was sought based on its relationship with two potential predictor variables: (i) the daily temperature range, which has previously been found to be a good indicator of cloud cover, and (ii) relative air humidity, which could reflect the attenuation by both water vapour and clouds (e.g. Dai et al. 1999, Pellicciotti et al. 2005). Several linear and nonlinear regression equations were tested with $\Delta T$ and $\mathrm{RH}$ as sole predictors, and with both variables as potential predictors.

\section{Albedo}

Snow albedo is an important factor governing the amount of solar energy absorbed by the surface. Since albedo measurements were only available for $2009 / 10$ at the study site, the albedo parameterization developed by Brock et al. (2000) was used to simulate albedo for the whole study period. The parameterization assumes that snow albedo $\left(\alpha_{s}\right)$ decays as a function of time and air temperature:

$$
\alpha_{\mathrm{s}}=p_{1}-p_{2}\left(\log _{10}(\mathrm{PDD})\right)
$$

where $\operatorname{PDD}\left(\mathrm{mm}^{\circ} \mathrm{C}^{-1} \mathrm{~d}^{-1}\right)$ is the positive degree-day sum since the last snowfall. The parameter $p_{1}$ represents a typical maximum albedo value for fresh snow, which in this study was fixed to 0.8 based on observations. The parameter $p_{2}$ was calibrated on daily albedo observations, by varying its value within a range between zero and one. Prior to calibration, raw hourly albedo observations were filtered to remove values with solar elevation angles less than $20^{\circ}$, or with reflected radiation less than $20 \mathrm{~W} \mathrm{~m}^{-2}$. This step removed all night-time values as well as early/late daytime values, when low Sun angles can cause large error in radiation measurements (Abermann et al. 2014). The resulting daytime albedo data were averaged to daily values.

\section{Model calibration and validation}

All melt model parameters were subjected to calibration. A systematic calibration procedure was used, which consisted in varying each parameter value within ranges determined from previous studies (Hock 2003, Pellicciotti et al. 2005, Gabbi et al. 2014). The parameter ranges were then extended if necessary, i.e. if the optimum value found was on the range boundary. The parameter ranges and increments used for the calibration step are listed in Table 1.

The SWE simulations were made at a daily time step during the snow season, from September to May, and compared with the measured SWE. Simulations were evaluated using the Nash-Sutcliffe efficiency measure (NSE). The optimum parameter values were chosen as those maximizing the NSE criterion during the calibration period, and the model performance was assessed during the independent validation period.

Two different approaches were adopted for model calibration and validation: annual and multi-annual calibration. The first approach, annual calibration, consisted in successively calibrating the models on each single year and validating on the remaining years. This is a variant of the split sample (SS) calibration/validation procedure (Klemeš 1986), which consists in dividing the period into two independent sub-periods for calibration and validation. This approach was used to examine the performance of each model when calibrated on a single year of measurements, and to detect possible model overfitting (e.g. Wagener et al. 2003) and its impact on model performance, as well as possible climate dependency of yearly-calibrated coefficients.

Table 1. Parameter ranges and value increments $(\Delta)$ used for the calibration of the four empirical models.

\begin{tabular}{|c|c|c|c|c|c|}
\hline Model & Parameter & Description & Unit & Range & $\Delta$ \\
\hline TI & DDF & Degree-day factor & $\mathrm{mm} \mathrm{d}^{-1}{ }^{\circ} \mathrm{C}^{-1}$ & $0.00-6.00$ & 0.1 \\
\hline \multirow[t]{2}{*}{ HTI } & MF & Melt factor & $\mathrm{mm} \mathrm{d}^{-1}{ }^{\circ} \mathrm{C}^{-1}$ & $0.00-6.00$ & 0.1 \\
\hline & $\mathrm{RF}$ & Potential radiation factor & $\mathrm{m}^{2} \mathrm{~mm} \mathrm{~W}^{-1} \mathrm{~d}^{-1}{ }^{\circ} \mathrm{C}^{-1}$ & $0.00-0.05$ & 0.0025 \\
\hline \multirow[t]{2}{*}{ ETI-A } & TF & Temperature factor & $\mathrm{mm} \mathrm{d}^{-1}{ }^{\circ} \mathrm{C}^{-1}$ & $0.00-6.00$ & 0.1 \\
\hline & $\mathrm{SRF}_{\text {in }}$ & Global radiation factor & $\mathrm{m}^{2} \mathrm{~mm} \mathrm{~W}^{-1} \mathrm{~d}^{-1}$ & $0.00-0.12$ & 0.005 \\
\hline \multirow[t]{2}{*}{ ETI-B } & TF & Temperature factor & $\mathrm{mm} \mathrm{d}^{-1}{ }^{\circ} \mathrm{C}^{-1}$ & $0.00-6.00$ & 0.1 \\
\hline & SRF $_{\text {net }}$ & Net shortwave radiation factor & $\mathrm{m}^{2} \mathrm{~mm} \mathrm{~W}^{-1} \mathrm{~d}^{-1}$ & $0.00-0.16$ & 0.005 \\
\hline
\end{tabular}


In the second approach, multi-annual calibration, models were successively calibrated on all 4-year sub-periods and validated on the left-out year. This "leave-one-year-out" cross-validation procedure allows the incorporation of natural climate variability in the calibration, and thus should reduce the dependence of parameters on climate conditions of the calibration period (Klemeš 1986, Coron et al. 2012).

\section{Parameter sensitivity}

Sensitivity analysis is often used to calibrate model parameters and assess how parameter uncertainty affects model performance, i.e. how model performance changes when moving away from an optimal parameter set (e.g. Paton et al. 2013). The sensitivity of the model performance, as measured by the NSE criterion obtained during multiyear calibration, to parameter variations within their calibration range, was examined graphically for the four melt models studied.

\section{Results}

\section{Calibration variables}

\section{Global radiation}

A positive relationship was found at Oukaimeden between the $R$ ratio and $\Delta T$, and a negative relationship between $R$ and $\mathrm{RH}$, however with a significant amount of scatter (Fig. 4).

Based on the coefficient of determination $\left(R^{2}\right)$ and variance ratio $(F)$ tests, a second-order polynomial regression with relative humidity as sole predictor was found to be the best parsimonious predictive model of the $R$ ratio $\left(R^{2}=0.52\right.$, RMSE $\left.=0.19\right)($ Fig. $4(\mathrm{~b}))$ :

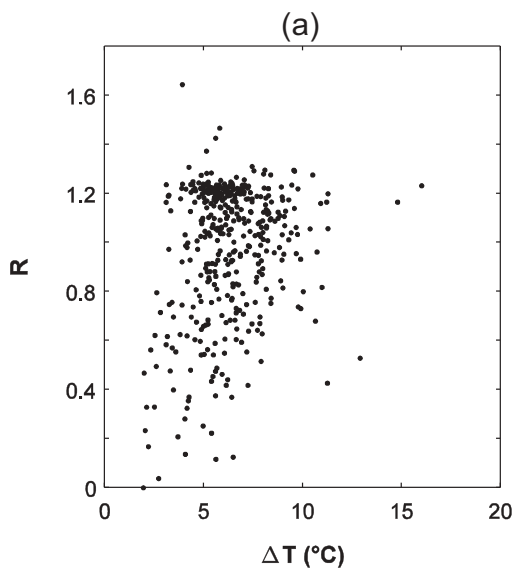

$$
R=-0.000054 \mathrm{RH}^{2}-0.0024 \mathrm{RH}+1.3
$$

Previous studies (Dai et al. 1999) have reported significant relationships between $\Delta T$ and cloud cover. On the Arolla and Gorner glaciers, in the Swiss Alps, Pellicciotti et al. (2011) found significant relationships between $\Delta T$ and computed daily cloud transmittance factors, with $\Delta T$ explaining $33-48 \%$ of the cloud transmissivity, depending on the year and location. They also found significant but weaker relationships between $\mathrm{RH}$ and cloud transmissivity $\left(R^{2}=13-41 \%\right)$. They used the $\Delta T$ relationship to parameterize the effect of cloud attenuation on the incoming shortwave radiation. In our case, including the diurnal temperature range did not improve the model and this term was thus neglected. Hence, while only half the variance of $R$ is explained by Equation (12), this results is in line with, and even superior to, previous findings and consequently can add significant predictive power to the ETI models, as found for example, by Pellicciotti et al. (2005).

\section{Albedo}

Globally, the agreement between modelled and measured albedo is fair during the snow season, except during peak events, where the simulated albedo does not reach some peaks due to the fixed value of $p_{1}$ at 0.8 (Fig. 5). A calibrated value of 0.21 was found for the $p_{2}$ coefficient, with RMSE of 0.098 and NSE of 0.80 .

\section{Model calibration and validation}

\section{Annual calibration}

All models performed equally well during annual calibration (NSE > 0.93) (Fig. 6(a)). However, validation statistics

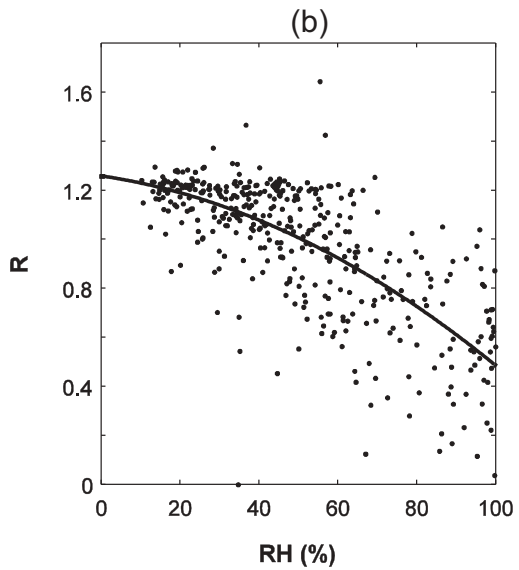

Figure 4. Scatter plot of the $R$ ratio against (a) daily temperature range $(\Delta T)$ and (b) relative humidity (RH) with second-order polynomial fit (see Equation (12)). 


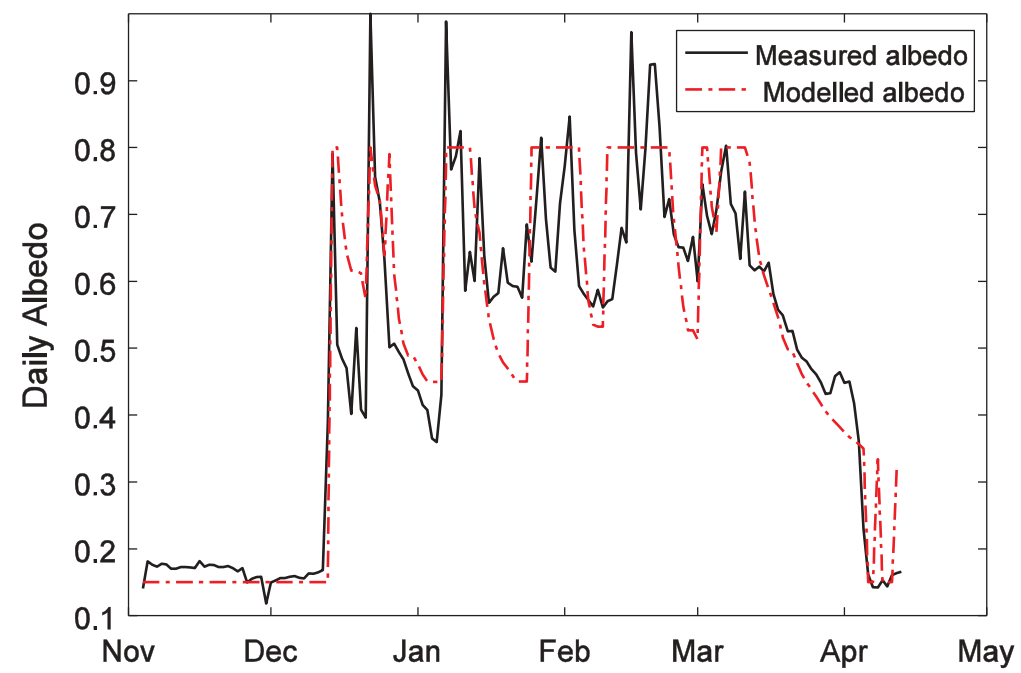

Figure 5. Measured and modelled daily mean albedo at Oukaimeden-SM station in 2009/10.
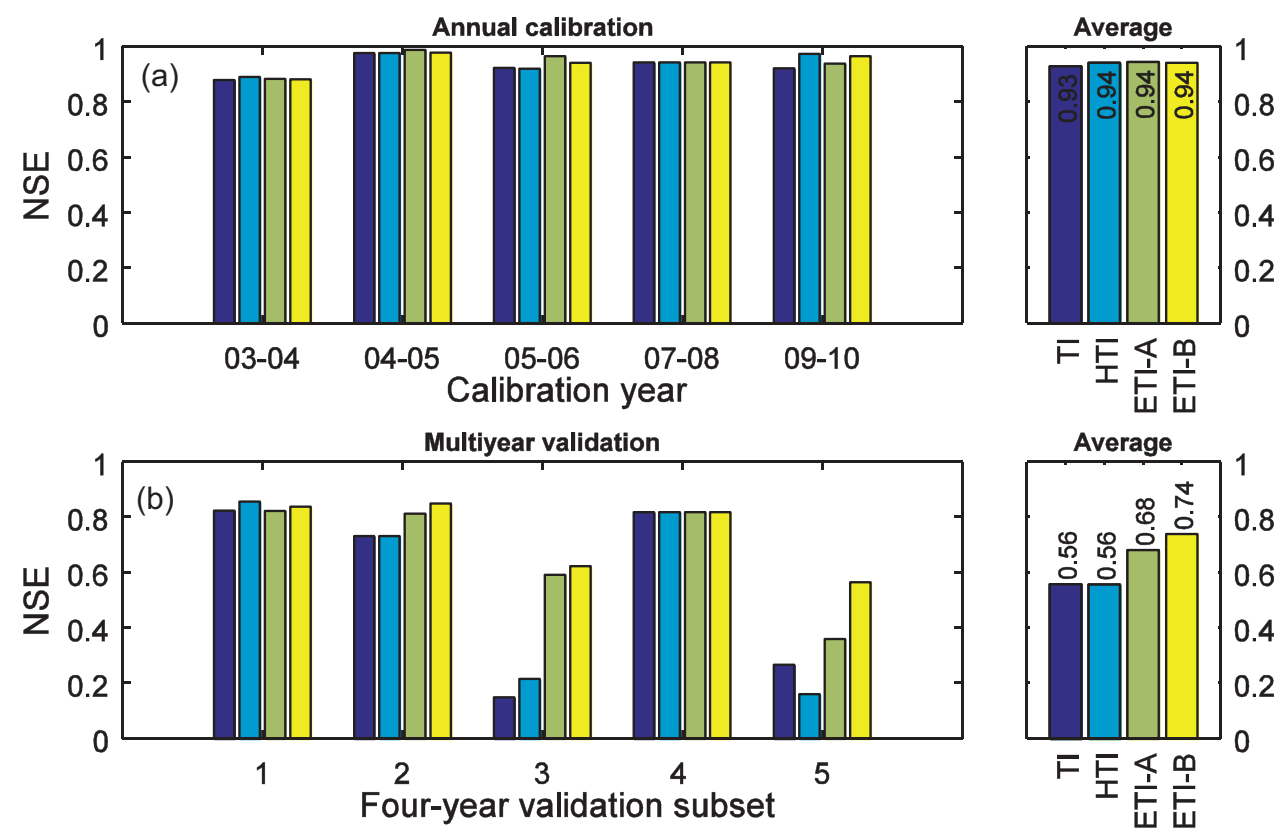

Figure 6. Comparison of the performance of the four melt models using annual calibration. (a) Nash-Sutcliffe efficiency (NSE) coefficient for annual calibration (left) and mean NSE across years (right); (b) 4-year-out validation NSE corresponding to each calibration year in (a) (left) and mean validation NSE across years (right).

show that the model performances outside the calibration period, and hence the parameter transferability, is very unequal among years and models, with the mean validation NSE across years varying from 0.56 to 0.74 (Fig. 6(b)). The two models that include radiation (ETI-A) and albedo (ETI-B) show overall better performance in the validation mode (mean NSE of 0.68 and 0.74 , respectively) than the TI and ETI models (mean NSE of 0.56). Hence, when calibrated on a single year both ETI models show better time transferability than the TI and HTI models, and the ETI-B model stands out as the best model. The generally poor transferability of yearly models can be observed further in Figure 7: the spread of SWE simulated by models calibrated yearly on other years is sometimes considerable (grey envelope), although it is reduced for the ETI models compared to both TI and HTI models. All models present the worst prediction performance, and hence worst transferability, when calibrated in 2005/06 and 2009/10, especially for the TI and HTI models (Fig. 6(b)). These two years were the two wettest in terms of mean relative humidity and peak SWE and also ranked first and third, respectively, in terms of total precipitation measured at the lower CAF station (Table 2, Fig. 7). Closer inspection of the simulated SWE record in 2005/06 shows that no 

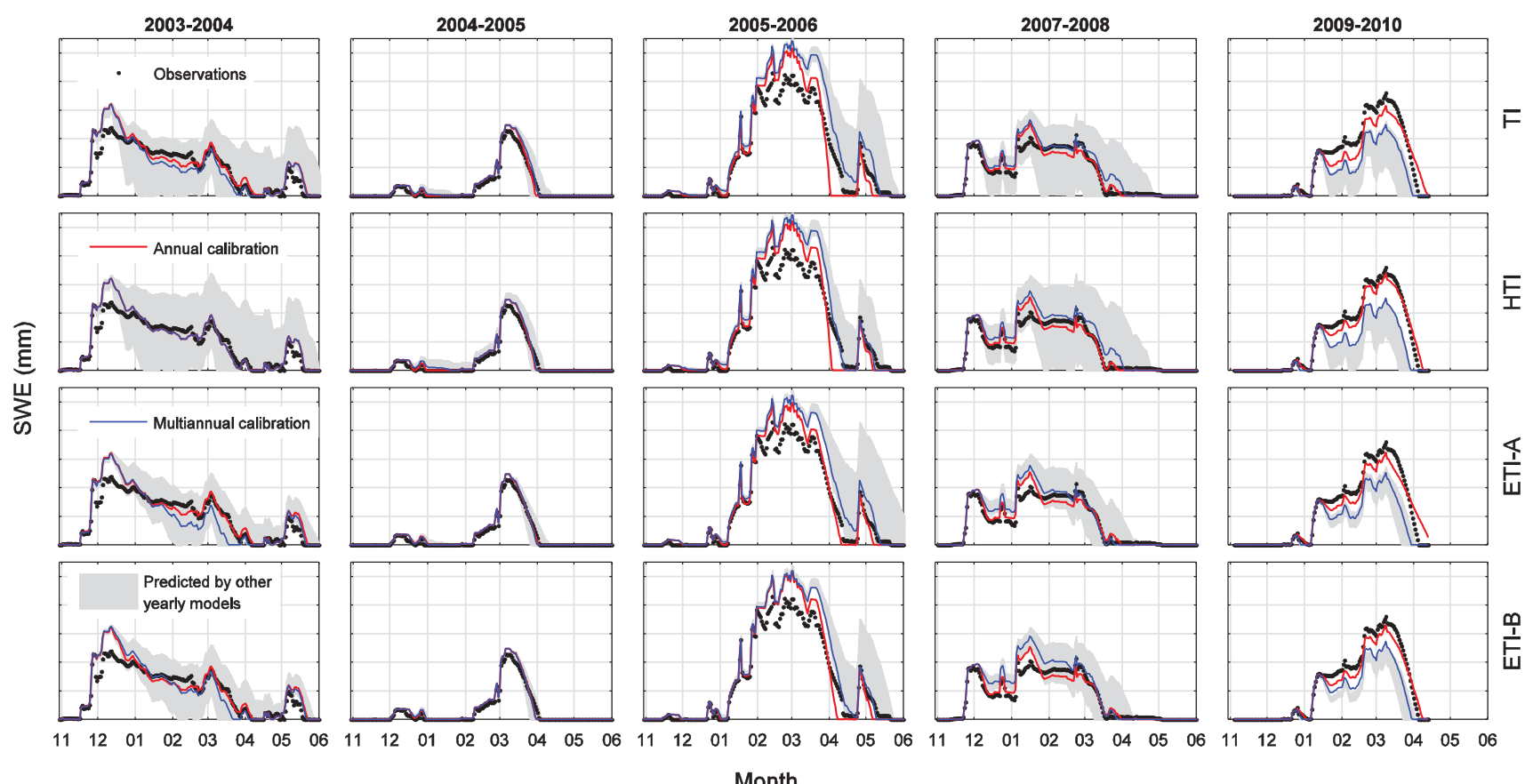

Month

Figure 7. Simulated vs observed SWE using the four melt models for the 2003-2010 period. Each row corresponds to one model and each column to a hydrological year. Black dots: observations; red line: annual calibration (Method 1); blue line: multi-annual calibration (Method 2); shaded area: range of SWE simulated by models calibrated yearly on other years.

melting was simulated in early February, while the observed SWE decreased; the cause of this error is unclear but could arise from an unfiltered erosion event, or from errors propagated from the conversion of snow depth to SWE. The positive bias introduced in the simulated SWE in winter was compensated by a higher-than-observed melt rate in the spring (Fig. 7). The opposite situation arose in 2009/10: melt rates appear exaggerated in winter and are compensated by slower-than-observed melt rates in the spring. In both instances, these biases in annual calibration resulted in poor model transferability. Interestingly both ETI models, while also showing a degraded performance, still performed significantly better than the TI and ETI models during those two years, which suggests that these humid years were also probably more cloudy and that models including a global radiation term are better suited to represent the varying energy inputs associated with changing cloud cover between years.

\section{Multi-annual calibration}

Calibrating the models on 4-year periods forces the models to better represent inter-annual climate variability, which results in a poorer model fit than yearly-calibrated models (mean calibration NSE across years $=0.84-0.88$ versus 0.93-0.94, Figs 6(a) and 8(a)). However, the independent validation, as performed with the leave-one-year-out cross-validation, shows that models are more transferable, as seen by the larger mean NSE across years (0.79-0.82)
(Fig. 8(b)) and reduced variability in model performance compared to annual calibration (Fig. 6(b)). Models calibrated on multi-annual periods (blue lines in Fig. 7) yield reasonable SWE simulations for independent years, compared to the spread in transferred yearly-calibrated models (blue lines $v s$ grey envelopes in Fig. 7).

Each model was recalibrated on the full 5-year period and annual melt rates computed (Table 3 ). Annual melt rates are on average higher for the HTI and ETI-A models than for the ETI-B and TI models, but ETI-B shows less variation between years than the other models, suggesting that including variations in snow albedo helps to better constrain inter-annual variations in melt rates. The sublimation ratio, using the prescribed sublimation rates (see Table 2), averaged $5.3 \pm 1.6 \%$ over the 5 -year period. Due to the oversimplified representation of sublimation in the models, the inter-annual variability is most likely underestimated.

\section{Parameter sensitivity and variability}

Model parameter sensitivity was analysed in terms of model error as measured by the NSE criterion obtained from multi-annual calibration on the whole 5-year dataset (Fig. 9). For two-parameter (enhanced) models, NSE contour plots allow assessing the effect of varying each model parameter on the calibration performance 
Table 2. Mean climate conditions and sublimation rates calculated for days with snow on the ground. RH: relative humidity; TP: total precipitation.

\begin{tabular}{lcccccc}
\hline Year & RH (\%) & Air temp. $\left({ }^{\circ} \mathrm{C}\right)$ & TP $^{\mathrm{a}}(\mathrm{mm})$ & Peak SWE $(\mathrm{mm})$ & Wind speed $\left(\mathrm{m} \mathrm{s}^{-1}\right)$ & Sublimation $^{\mathrm{b}}\left(\mathrm{mm} \mathrm{d}^{-1}\right)$ \\
\hline $2003 / 04$ & 42.9 & 1.18 & 466 & 240 & 2.54 & 0.26 \\
$2004 / 05$ & 52.3 & -1.92 & 168 & 229 & 2.72 & 0.18 \\
$2005 / 06$ & 55.1 & 0.61 & 503 & 430 & 2.91 & 0.29 \\
$2007 / 08$ & 44.5 & 0.74 & 291 & 214 & 2.84 & 0.21 \\
$2009 / 10$ & 52.6 & 0.93 & 312 & 360 & 2.67 & 0.17 \\
\hline
\end{tabular}

${ }^{\mathrm{a}}$ at CAF station. ${ }^{\mathrm{b}}$ from Boudhar et al. (2016).
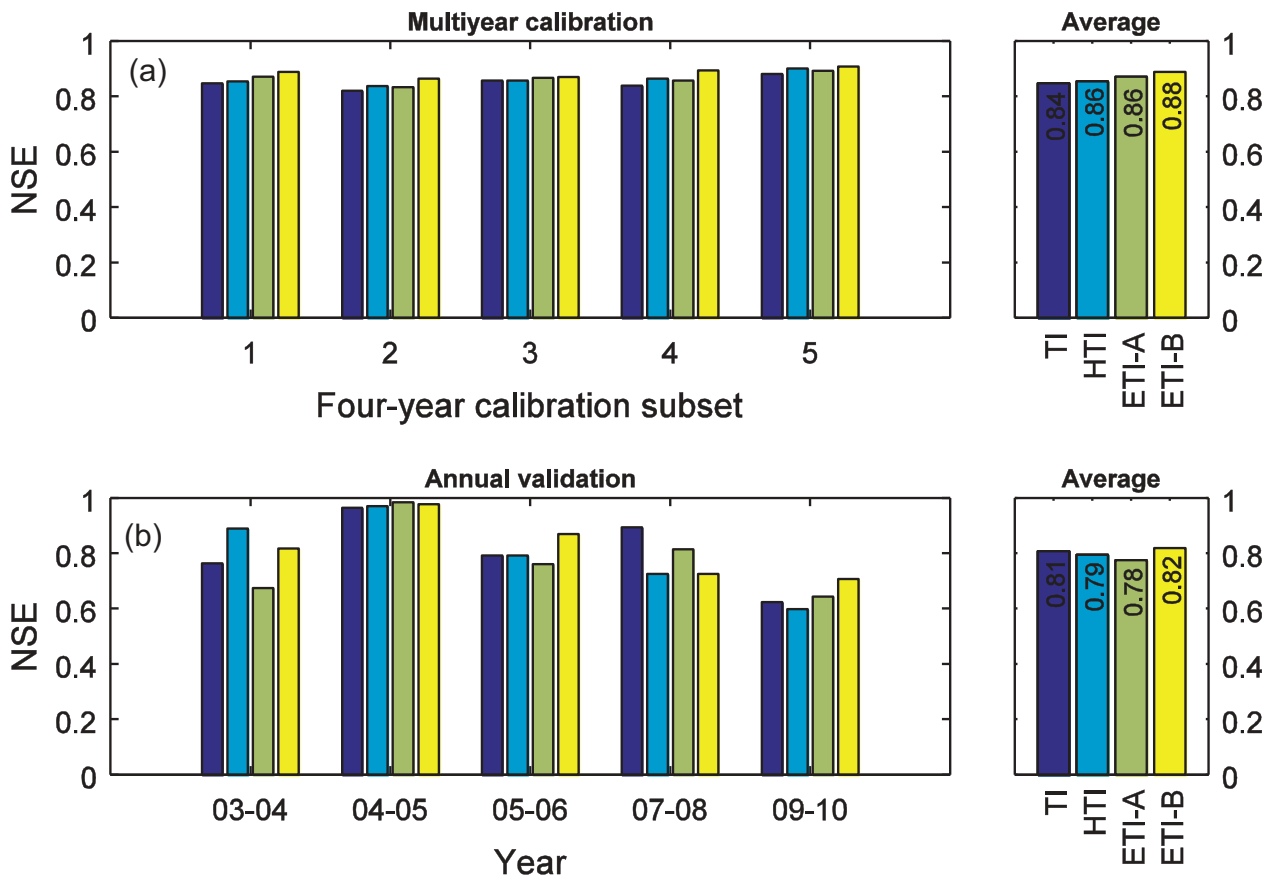

Figure 8. Comparison of the performance of the four melt models using multi-annual calibration. (a) Nash-Sutcliffe efficiency (NSE) coefficient for each 4-year calibration sub-period (left) and mean calibration NSE by model (right); and (b) validation NSE on the year left out from the calibration subset in (b) (left) and mean leave-one-year-out validation NSE by model (right).

Table 3. Mean daily melt rates for each year, calculated using the 5-year calibrated models. The constant daily sublimation rates listed in Table 2 were used to calculate the sublimation ratios. SD: standard deviation.

\begin{tabular}{lccccc}
\hline & \multicolumn{3}{c}{ Melt } & All models \\
\cline { 2 - 5 } Year & $\mathrm{TI}\left(\mathrm{mm} \mathrm{d}^{-1}\right)$ & $\mathrm{HTI}\left(\mathrm{mm} \mathrm{d}^{-1}\right)$ & ETI-A $\left(\mathrm{mm} \mathrm{d}^{-1}\right)$ & ETI-B $\left(\mathrm{mm} \mathrm{d}^{-1}\right)$ & Mean sublimation ratio \pm SD (\%) \\
\hline $2003 / 04$ & 5.6 & 6.1 & 6.1 & 5.0 & $4.9 \pm 0.4$ \\
$2004 / 05$ & 2.8 & 2.7 & 3.4 & 3.4 & $6.2 \pm 0.7$ \\
$2005 / 06$ & 4.9 & 5.3 & 5.3 & 5.3 & $5.6 \pm 0.2$ \\
$2007 / 08$ & 3.3 & 3.3 & 3.7 & 3.5 & $7 \pm 0.3$ \\
$2009 / 10$ & 5.6 & 5.7 & 5.8 & 5.2 & $2.7 \pm 0.1$ \\
Mean \pm SD & $4.4 \pm 1.3$ & $4.6 \pm 1.5$ & $4.8 \pm 1.2$ & $4.5 \pm 1$ & $5.3 \pm 1.6$ \\
\hline
\end{tabular}

of the SWE simulations. The optimal parameter sets obtained from annual calibration were also overlain on NSE contour plots to investigate their variability with respect to the multi-annual calibration optimum. The three enhanced models are seen to be equally sensitive to both temperature and radiation. However, while an optimum was found for all models using multi-annual calibration, equifinality is also apparent for the twoparameter models, with different combinations of temperature and radiation-related parameters resulting in a high NSE criterion. The optimum is clearest for the ETI-B model (Fig. 9(d)).

Optimal parameters obtained from annual calibration (Method 1) show considerable inter-annual variability, with the respective contributions of the radiation and temperature terms changing between years for a given model (Fig. 9). Several of the optimal annual parameter sets are found along the high NSE diagonal band found 
(a)

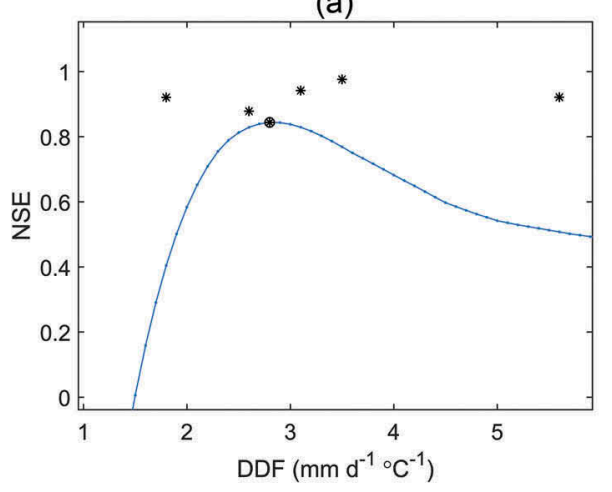

(c)

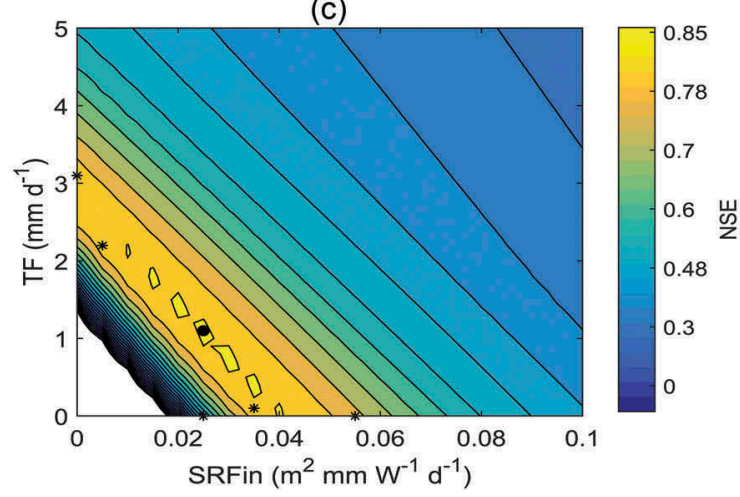

(b)

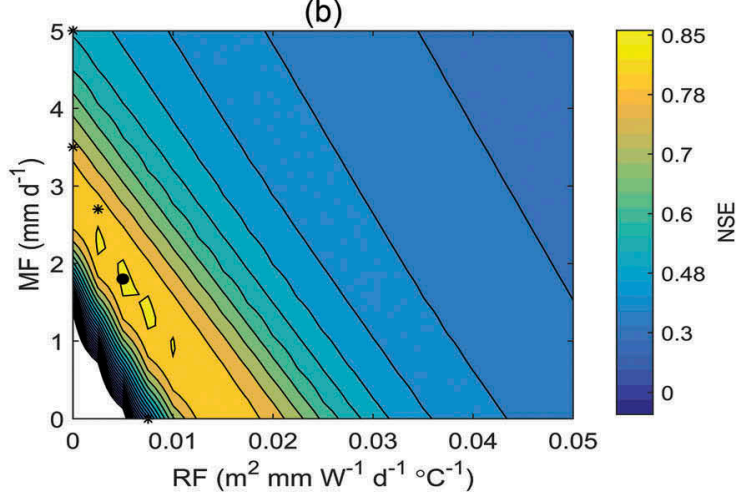

(d)

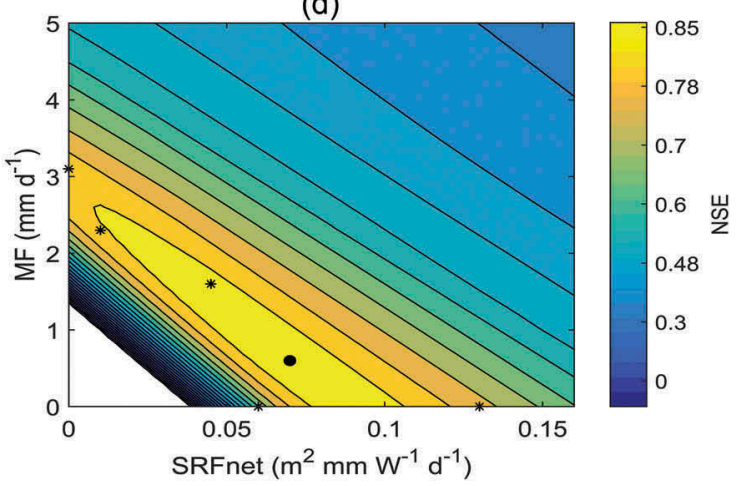

Figure 9. Sensitivity of model performance to parameter variations (see Table 1). The model performance is assessed with the NSE criterion using calibration over the full 5-year period. (a) TI model; (b) HTI model; (c) ETI-A model; (d) ETI-B model. Optimal parameter values from multi-annual calibration are indicated by a black dot; yearly calibrated parameters are overlain onto the contour plot and indicated by asterisks $\left(^{*}\right)$.

from multi-annual calibration, which suggests that at least some of the inter-annual variability in annual coefficients could be due to equifinality. However, deviations also occur, especially for the additive ETI models, which also suggests that the respective contributions of temperature and radiation to snowmelt may change between years in response to climatic conditions, as found for example by Gabbi et al. (2014).

The inter-annual variability of model parameter values resulting from the annual calibration (Method 1) is further investigated in Figure 10. The temperature factor of both the TI and HTI models exhibit a similar tendency over the five studied seasons, increasing until 2005/06 and decreasing afterward. The pattern is different for the ETI models. Both models show a maximum $\mathrm{TF}$ value $\left(3 \mathrm{~mm} \mathrm{~d}^{-1}{ }^{\circ} \mathrm{C}^{-1}\right)$ in $2007 / 08$. The TF factor is nil in 2004/05 for ETI-A and in 2005/06 for both models. The radiation factor $\left(\mathrm{SRF}_{\mathrm{in}}, \mathrm{SRF}_{\text {net }}\right)$ varies inversely with the temperature factor. Whether these annual variations in model parameters are related to climate conditions prevailing in a given year, or are simply caused by overfitting the models in each single year and/or parameter compensation (i.e. equifinality) is investigated in the next section.

\section{Relationship between annual parameters and climate}

The dependence of model parameters on climatic conditions was investigated using simple bivariate correlation analysis between the yearly-calibrated model parameters and annual averages of measured meteorological variables (air temperature, relative humidity, total precipitation, wind speed) as well as with the mean daily sublimation rate used in the model formulation (Table 2). The averages were calculated for days with snow on the ground only. The scope of this analysis is evidently limited by the small number of observations (5 years), but is nonetheless instructive to reveal possible climate control on annual parameter variations. The TF and $\mathrm{SRF}_{\text {in }}$ factors in the ETI-A model show statistically significant $(p<0.05)$ negative and positive correlation with relative humidity, respectively. The same pattern is found for the ETI-B model, albeit with weaker correlations $(p<0.10)$. For the three enhanced models the temperature and radiation factors are inversely correlated, reflecting the pattern seen in Figure 10. This parameter compensation is strongest for the HTI and weakest for the ETI-B model. 

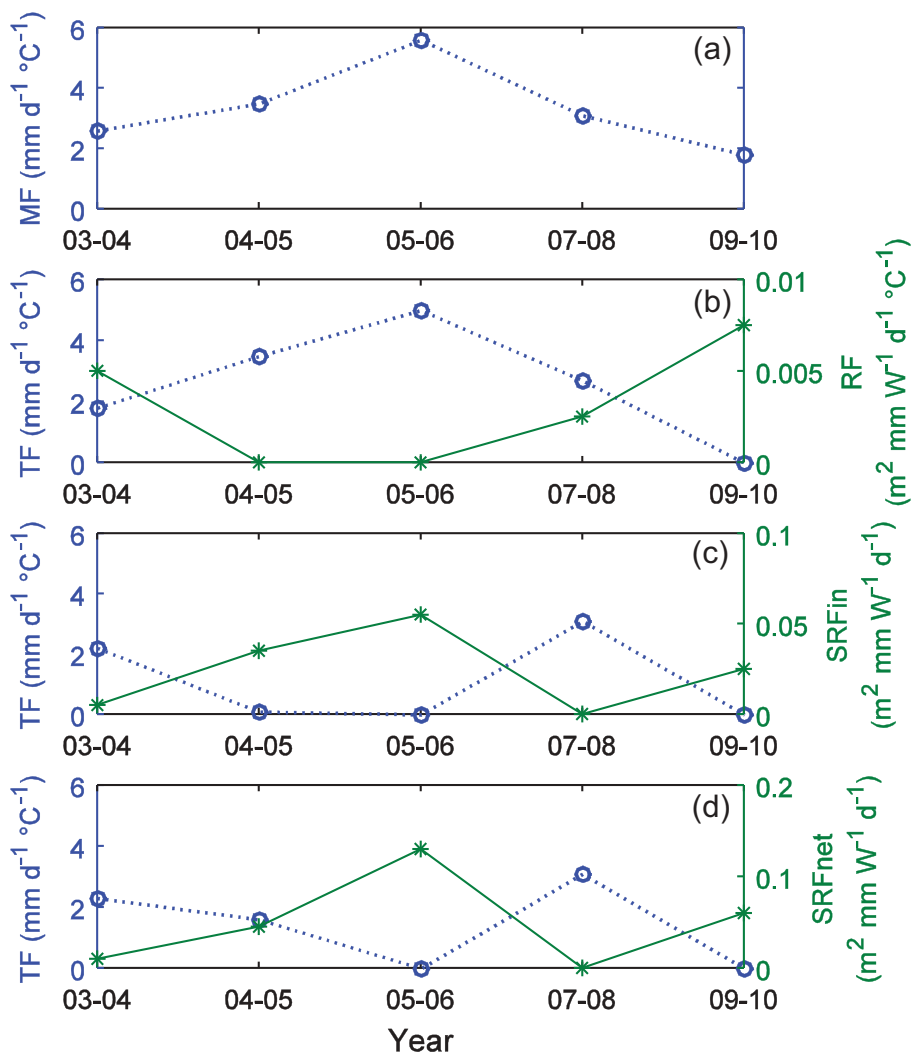

Figure 10. Yearly calibrated model parameters for the (a) TI, (b) HTI, (c) ETI-A and (d) ETI-B models for five hydrological years.

\section{Discussion}

\section{Model performance and transferability}

Taken together our results show that when calibrating models on a restricted dataset such as a single year of measurement, a situation not uncommon at remote sites, enhanced additive models such as ETI are more transferable than simpler models such as TI and HTI, which are predominantly temperature-based models (Fig. 6). At a point scale, the sole effect of including a potential radiation term in the HTI is to progressively augment the TF factor as solar radiation increases toward its summer maximum. But explicit consideration of the atmospheric transmissivity (via the $R$ ratio in both ETI models), and of snow albedo in the ETI-B, appears to better capture the intra-season variability in melt rate arising from changes in the contributions of shortwave radiation versus temperaturedependent longwave and sensible heat fluxes to the snow surface energy balance. The fact that the additive ETI models are better transferred from one year to another is somewhat surprising given the significant variability of the yearly calibrated parameters. The explanation may reside in the fact that several combinations of the temperature and radiation factors give similarly acceptable model performance (Fig. 9), i.e. equifinal solutions (Beven 2006), and hence a given combination of parameters fitted to one particular year has a good chance to give acceptable predictions when applied to a different year. Conversely, the simpler temperature-dependent TI and HTI models are less able to represent changes in energy fluxes induced by varying cloud cover and albedo, and will thus exacerbate model overfitting when calibrated on short intervals, making them less transferable between years.

However, when calibration is performed on a longer period that incorporates at least some interannual climatic variability, all models perform equally well, and no model clearly stands out as optimal (Fig. 8). It is noteworthy, however, that the simplest model TI has the second highest performance $(\mathrm{NSE}=0.81)$ behind the ETI-B model $(\mathrm{NSE}=0.82)$. These results are in agreement with those of Pellicciotti et al. (2005), who suggested that ETI models are more transferable over time, whereas e.g. Réveillet et al. (2016) concluded instead that TI models are the most efficient models overall for predicting snow and ice melt on glaciers, when calibrated on a long period ( $>10$ years). Our results tend to corroborate these findings, i.e. that simple TI models, when calibrated on a period long enough to capture interannual climate variability, offer good performance at the station scale, comparable and even superior to some enhanced models. 


\section{Parameter variability and climate dependency}

Our results showed pronounced inter-annual variability in yearly-calibrated model parameters. Lang and Braun (1990) and Hock (2003) report that, under otherwise similar conditions, degree-day factors are expected to increase in response to increased solar radiation input and decreased albedo, and that higher shares of sensible heat flux in the heat balance are generally associated with low degree-day factors and vice versa. No such simple relation emerged between the temperature factor of the TI model and climate conditions at the Oukaimeden site. For the ETI-A model, and the ETI-B model to a lesser extent, a positive and negative correlation emerged between relative humidity and the radiation and temperature factor, respectively. Inter-parameter correlations show that radiation and temperature factors in enhanced models compensate each other; this effect is most pronounced for the HTI model, which is rather expected since both factors are used as the multiplier of the temperature (see Equation (6)), different from the two ETI models.

Strong parameter compensation (equifinality) was observed for all the enhanced models (Fig. 9, Table 4). The same compensation between temperature- and radiation-based parameters was previously reported and discussed by Gabbi et al. (2014) and Réveillet et al. (2016). However, Gabbi et al. (2014) attributed inter-annual variations in parameters to climate conditions, finding for the ETI-B model that the temperature factor was higher and the radiation factor lower in years with reduced solar radiation. They interpreted this relationship as resulting from a decreased influence of solar radiation, and respective increased influence of incoming longwave and sensible heat fluxes on melt during more humid and cloudy years, in line with previous findings by Carenzo et al. (2009). No such relationship emerged in our analyses; moreover, more humid conditions, which are associated with reduced solar radiation via the $R$ ratio parameterization (see Equation (12)), were found to promote a larger radiation factor and smaller temperature factor in the ETI models, which is opposite to the aforementioned results found by Gabbi et al. (2014).
Interestingly, the correlation between relative humidity and both TF and SRF is reduced in the ETI-B model when the albedo is considered (Table 4).

In light of these results, we suggest that much of the inter-annual variability in the yearly-calibrated coefficients is due to model overfitting errors in a given year. Including a solar radiation term (incoming or net) seems to reduce this phenomenon and allows the calibrated models to be better transferred to other years. This improved transferability is in part inherited from the equifinality of the temperature and radiation factors, whereas several pairs of parameters give similarly acceptable predictions. However, it also implies that parameters are not well defined, and hence that year-to-year climate variations and/or measurement errors can cause significant differences in the contributions of the melt and radiation factors to snowmelt. This phenomenon may be explained by the partial collinearity of air temperature and incoming solar radiation, an aspect that has been overlooked in the literature when discussing the calibration of empirical melt models. In statistics, collinearity is a phenomenon in which one predictor variable in a multiple regression model can be linearly predicted from the others with a substantial degree of accuracy. It does not reduce the predictive power or reliability of the model as a whole, at least within the sample data, but will increase the uncertainty of model parameters. In such situation the standard error for the regression coefficient of a given predictor increases by a factor equal to $\sqrt{\mathrm{VIF}}$, where VIF is the variance inflation factor of the predictor, equal to $1 /\left(1-R^{2}\right)$, and $R^{2}$ is the coefficient of determination of the regression of the predictor against all other predictors (e.g. Draper and Smith 1998). Variables with VIF $>5$ are typically flagged as collinear. The presence of collinear variables in a linear model makes the model more prone to overfitting, i.e. the model coefficients can vary significantly between different calibration samples. However, such a model can still yield good predictive performance outside the calibration interval, especially if the collinearity between the predictors is maintained. Strictly, statistical theory does not apply in this case as the model parameters were not derived using the least square method. Nonetheless, the linear structure of the additive

Table 4. Pearson correlation coefficients between climatic variables and annual model parameters.

\begin{tabular}{|c|c|c|c|c|c|c|c|}
\hline \multirow[b]{2}{*}{ Climatic variables \& parameters } & \multirow{2}{*}{$\frac{\mathrm{TI}}{\mathrm{DDF}}$} & \multicolumn{2}{|c|}{ HTI } & \multicolumn{2}{|c|}{ ETI-A } & \multicolumn{2}{|l|}{ ETI-B } \\
\hline & & TF & RF & TF & $\mathrm{SRF}_{\text {in }}$ & TF & $\mathrm{SRF}_{\text {net }}$ \\
\hline Air temperature $\left({ }^{\circ} \mathrm{C}\right)$ & -0.19 & -0.38 & 0.61 & 0.41 & -0.37 & -0.03 & -0.06 \\
\hline Relative humidity (\%) & 0.47 & 0.31 & -0.31 & $-0.93^{* *}$ & $0.93^{* *}$ & $-0.87^{*}$ & $0.88^{*}$ \\
\hline Total precipitation $(\mathrm{mm})^{\mathrm{a}}$ & 0.74 & 0.68 & -0.64 & -0.11 & 0.47 & -0.18 & 0.52 \\
\hline Wind speed $\left(\mathrm{m} \mathrm{s}^{-1}\right)$ & 0.39 & 0.20 & 0.10 & 0.08 & 0.15 & -0.25 & 0.39 \\
\hline Sublimation $\left(\mathrm{mm} \mathrm{d}^{-1}\right)$ & 0.65 & 0.64 & -0.44 & 0.40 & 0.04 & 0.24 & 0.16 \\
\hline Inter-parameter correlation & n.a. & \multicolumn{2}{|c|}{$-0.95^{* *}$} & \multicolumn{2}{|c|}{$-0.87^{*}$} & \multicolumn{2}{|c|}{$-0.86^{*}$} \\
\hline
\end{tabular}

a at CAF station. ${ }^{* *} p<0.05 ;{ }^{*} p<0.10$. 
ETI models and the systematic calibration procedure that minimizes prediction errors is much akin to the multiple regression framework. Over the whole study period, air temperature was found to be positively and significantly $(p<0.01)$ correlated with the potential $(r=0.44)$, global $(r=0.65)$ and net shortwave $(r=0.74)$ radiation, considering only the days with snow on the ground. This gives VIF factors of 1.73 and 2.21 for the ETI-A and ETI-B models, respectively. This is of course to be expected, as apart from the heat flux from advected air masses the air temperature depends on the longwave radiation emitted from the surface and upward convection of sensible and latent heat, all of which depend, albeit in a complex manner, on the surface shortwave radiation balance. Hence, air temperature and solar radiation "share" a significant fraction of the snowmelt predictive power and as such are partly redundant predictors. The VIF factors point only to moderate, but still significant, collinearity of these two variables in the linear ETI models. This may confuse the identifiability of parameters and increase their uncertainty when calibrated on short intervals. This collinearity explains the parameter compensation and equifinality observed in this study (Fig. 10, Table 4) and probably that observed in previous ones (Gabbi et al. 2014). The fact that both ETI models were found to be better transferred to other years when calibrated yearly can be explained on the one hand by the true, non-redundant predictive contribution of the solar radiation term, and on the other by the fact that the collinearity between air temperature and solar radiation is maintained in other years.

\section{Conclusion}

This study presented an application of four empirical melt models at a remote study site in the Moroccan High Atlas. A classical simple degree-day model (TI) and three "enhanced" melt models combining air temperature and different solar radiation terms (HTI, ETIA and ETI-B) were tested and compared. Owing to the lack of long-term meteorological data, especially shortwave radiation and albedo, simple parameterizations were developed to represent these variables in the snowmelt models. The shortwave radiation was parameterized using the calculated potential clear-sky direct solar radiation multiplied by a bulk atmospheric transmissivity term ( $R$ ratio). A good relationship was found between the $R$ ratio and relative humidity, which allowed estimation of the global solar radiation over the entire period. The snow albedo was parameterized with a simple temperature-dependent function (Brock et al. 2000), which showed satisfactory performance against available measurements. Hence, the snowmelt models tested grow in complexity and physical realism from the simple, one-parameter TI model to the twoparameter ETI-B model, which includes parameterizations for atmospheric transmissivity and surface albedo while conserving a parsimonious data requirement, which is crucial for applications in the high Atlas. The four models were subjected to different cross-calibration-validation methods over the 2003-2010 period, and the parameter sensitivity and model transferability over time were assessed. The main results and conclusions of our work are as follows:

(1) When calibrated on a yearly basis, all models performed well (NSE > 0.93) in calibration mode but the enhanced additive models performed better in validation mode $(\mathrm{NSE}=0.68-0.74)$ than the TI and HTI models (NSE $=0.56$ ) and were thus deemed to be better transferable over time.

(2) The leave-one-year-out cross-validation procedure showed that models are more transferable when calibrated on a longer period that includes some inter-annual climate variability; all models performed well in validation mode (NSE $=0.78$ 0.82 ), with the ETI-B model (NSE $=0.82$ ) only slightly outperforming the simpler TI model $(\mathrm{NSE}=0.81)$. Hence, temporal variations in snowmelt could be adequately reproduced when sufficiently long periods are available for calibration of the TI model, as suggested recently by Réveillet et al. (2016).

(3) Notable annual variations were found in yearlycalibrated model parameters and only marginal connections emerged between yearly-calibrated parameters and climate conditions. While the short period (5 years) inherently precludes a more conclusive analysis, it is suggested that the collinearity of air temperature and solar radiation are responsible for much of this variability; fitting collinear variables on observations affected by measurement uncertainties will cause large variations in calibrated parameters. This collinearity causes parameters to compensate each other and gives rise to equifinality between the temperature and radiation-based factors. This same equifinality may explain why different yearly-calibrated parameter combinations yield acceptable performance when transferred to other years. Further investigation of the impact of this collinearity on the identifiability and transferability of melt model parameters is warranted, hopefully at sites with longer and higher quality data series.

(4) Despite the highlighted equifinality phenomenon, the ETI-B model stands out as the best 
model overall. While its performance was only marginally superior to the simple TI model when calibrated on multiyear intervals, it performed better than other models when calibrated on short (1-year) intervals. The added value of including a radiation term for better simulating the spatial variability of snow cover will be assessed in upcoming work.

\section{Acknowledgements}

The authors would like to thank the Joint International Laboratory TREMA (http://trema.ucam.ac.ma) for providing snow and meteorological data. They also thank Dr Steven R. Fassnacht and two anonymous reviewers who helped to improve the quality of this manuscript.

\section{Disclosure statement}

No potential conflict of interest was reported by the authors.

\section{Funding}

This work was jointly funded by the Agence Universitaire pour la Francophonie (AUF) - Programme de petites initiatives de recherche, d'animation et de transfert (PIRAT), the Natural Sciences and Engineering Research Council of Canada (NSERC). Support was provided by the CNRST (Centre National pour la Recherche Scientifique et Technique of Morocco) to H. Bouamri as a PhD scholarship. S. Gascoin is supported by the CNES through the TOSCA programme.

\section{References}

Abermann, J., Kinnard, C., and MacDonell, S., 2014. Albedo variations and the impact of clouds on glaciers in the Chilean semi-arid Andes. Journal of Glaciology, 60 (219), 183-191. doi:10.3189/2014JoG13J094

Abudu, S., et al., 2012. Application of snowmelt runoff model (SRM) in mountainous watersheds: a review. Water Science and Engineering, 5, 123-136.

Bales, R.C., et al., 2006. Mountain hydrology of the western United States. Water Resources Research, 42, 1-13. doi:10.1029/2005WR004387

Barnett, T.P., Adam, J.C., and Lettenmaier, D.P., 2005. Potential impacts of a warming climate on water availability in snow-dominated regions. Nature, 438, 303-309. doi:10.1038/nature04141

Beven, K., 1993. Prophecy, reality and uncertainty in distributed hydrological modeling. Advances in Water Resources, 16, 41-51. doi:10.1016/0309-1708(93)90028-E

Beven, K., 2006. A manifesto for the equifinality thesis. Journal of Hydrology, 320, 18-36. doi:10.1016/j.jhydrol.2005.07.007

Binley, A., et al., 1997. Modelling uncertainty in estimates of recharge to a shallow coastal aquifer. Hydrological Sciences Journal, 42, 155-168. doi:10.1080/02626669709492017
Boudhar, A., et al., 2009a. Evaluation of the snowmelt runoff model in the Moroccan high Atlas Mountains using two snow-cover estimates. Hydrological Sciences Journal, 54, 1094-1113. doi:10.1623/hysj.54.6.1094

Boudhar, A., 2009b. Télédétection du manteau neigeux et modélisation de la contribution des eaux de fonte des neiges aux débits des Oueds du Haut Atlas de Marrakech. (PhD). University Cadi Ayyad.

Boudhar, A., et al., 2016. Energy fluxes and melt rate of a seasonal snow cover in the Moroccan High Atlas. Hydrological Sciences Journal, 61, 931-943.

Brock, B.W., Willis, I.C., and Sharp, M.J., 2000. Measurement and parameterization of albedo variations at Haut Glacier d ' Arolla, Switzerland. Journal of Glaciology, 46, 675-688. doi:10.3189/172756500781832675

Brubaker, K., Rango, A., and Kustas, W., 1996. Incorporating radiation inputs into the snowmelt runoff model. Hydrological Processes, 10, 1329-1343. doi:10.1002/(ISSN)1099-1085

Carenzo, M., et al., 2009. Assessing the transferability and robustness of an enhanced temperature-index glacier-melt model. Journal of Glaciology, 55 (190), 258-274. doi:10.3189/002214309788608804

Chehbouni, A., et al., 2008. An integrated modelling and remote sensing approach for hydrological study in arid and semi-arid regions: the SUDMED programme. International Journal of Remote Sensing, 29, 5161-5181. doi:10.1080/01431160802036417

Coron, L., et al., 2012. Crash testing hydrological models in contrasted climate conditions: an experiment on 216 Australian catchments. Water Resources Research, 48, 117. doi:10.1029/2011WR011721

Cudennec, C., Leduc, C., and Koutsoyiannis, D., 2007. Dryland hydrology in Mediterranean regions a review. Hydrological Sciences, 52, 1077-1087. doi:10.1623/hysj.52.6.1077

Dai, A., Trenberth, K.E., and Karl, T.R., 1999. Effects of clouds, soil moisture, precipitation, and water vapor on diurnal temperature range. Journal of Climate, 12, 2451-2473. doi:10.1175/1520-0442(1999)012<2451:EOCSMP>2.0.CO;2

de Jong, C., et al., 2008. A transdisciplinary analysis of water problems in the mountainous karst areas of Morocco. Engineering Geology, 99, 228-238. doi:10.1016/ j.enggeo.2007.11.021

DeWalle, D. and Rango, A., 2008. Principles of snow hydrology. New York, NY: Cambridge University Press.

Draper, N.R. and Smith, H., 1998. Applied regression analysis. 3rd. New York, NY: John Wiley \& Sons, Inc.

Fassnacht, S., et al., 2017. Spatio-temporal snowmelt variability across the headwaters of the southern rocky mountains. Frontiers of Earth Science, 11 (3), 505-514. doi:10.1007/s11707-017-0641-4

Fassnacht, S.R., 2004. Estimating Alter-shielded gauge snowfall undercatch, snowpack sublimation, and blowing snow transport at six sites in the coterminous USA. Hydrological Processes, 18 (18), 3481-3492. doi:10.1002/ (ISSN)1099-1085

Fayad, A., et al., 2017. Snow hydrology in Mediterranean mountain regions: a review. Journal of Hydrology, 551, 374-396. doi:10.1016/j.jhydrol.2017.05.063

Franz, K.J., Butcher, P., and Ajami, N.K., 2010. Addressing snow model uncertainty for hydrologic prediction. Advances in Water Resources, 33 (8), 820-832. doi:10.1016/j.advwatres.2010.05.004 
Froyland, H.K., 2013. Snow loss on the san francisco peaks: Effects of an elevation gradient on evapo-sublimation. (Master of Science). Northern Arizona University.

Gabbi, J., et al., 2014. A comparison of empirical and physically based glacier surface melt models for long-term simulations of glacier response. Journal of Glaciology, 60 (224), 1140-1154. doi:10.3189/2014JoG14J011

Gascoin, S., et al., 2013. Wind effects on snow cover in Pascua-Lama, Dry Andes of Chile. Advances in Water Resources, 55, 25-39. doi:10.1016/j.advwatres.2012.11.013

He, Z.H., et al., 2014. Estimating degree-day factors from MODIS for snowmelt runoff modeling. Hydrology and Earth System Sciences, 18 (12), 4773-4789. doi:10.5194/ hess-18-4773-2014

Herrero, J., et al., 2009. An energy balance snowmelt model in a Mediterranean site. Journal of Hydrology, 371 (1-4), 98-107. doi:10.1016/j.jhydrol.2009.03.021

Herrero, J. and Polo, M.J., 2016. Evaposublimation from the snow in the Mediterranean mountains of Sierra Nevada (Spain). The Cryosphere, 10 (6), 2981-2998. doi:10.5194/ tc-10-2981-2016

Hock, R., 1999. A distributed tetn.perature-index ice- and snowrnelt tn.odel including potential direct solar radiation. Journal of Glaciology, 45, 101-111. doi:10.1017/ S0022143000003087

Hock, R., 2003. Temperature index melt modelling in mountain areas. Journal of Hydrology, 282, 104-115. doi:10.1016/S0022-1694(03)00257-9

Hock, R., 2005. Glacier melt: a review of processes and their modelling. Progress in Physical Geography, 29, 362-391. doi:10.1191/0309133305pp453ra

Hock, R. and Holmgren, B., 2005. A distributed surface energy-balance model for complex topography and its application to Storglaciaren,Sweden. Journal of Glaciology, 51, 25-36. doi:10.3189/172756505781829566

Hock, R. and Noetzli, C., 1997. Areal melt and discharge modelling of StorglacHiren, Sweden. International Glaciological Society, 24, 211-216.

Homan, J.W., et al., 2011. Improvement of distributed snowmelt energy balance modeling with MODIS-based NDSIderived fractional snow-covered area data. Hydrological Processes, 25 (4), 650-660. doi:10.1002/hyp.7857

Hublart, P., et al., 2016. Reliability of lumped hydrological modeling in a semi-arid mountainous catchment facing water-use changes. Hydrology and Earth System Sciences, 20, 3691-3717. doi:10.5194/hess-20-3691-2016

Huss, M., Funk, M., and Ohmura, A., 2009. Strong Alpine glacier melt in the 1940s due to enhanced solar radiation. Geophysical Research Letters, 36, 23. doi:10.1029/ 2009GL040789

Jarlan, L., et al., 2015. Remote sensing of water resources in semi-arid Mediterranean areas: the joint international laboratory TREMA. International Journal of Remote Sensing, 36, 4879-4917. doi:10.1080/01431161.2015.1093198

Kampf, S.K. and Richer, E.E., 2014. Estimating source regions for snowmelt runoff in a Rocky Mountain basin: tests of a data-based conceptual modeling approach. Hydrological Processes, 28 (4), 2237-2250. doi:10.1002/ hyp.9751

King, J.C., et al., 2008. Snow-atmosphere energy and mass balance. In: R.L. Armstrong and E. Brun, eds. Snow and climate: Physical processes, surface energy exchange and modelling. New York, NY: Cambrige University Press. 70-124.

Klemeš, V., 1986. Operational testing of hydrological simulation models. Hydrological Sciences Journal, 31 (1), 13-24. doi:10.1080/02626668609491024

Knippertz, P., Christoph, M., and Speth, P., 2003. Long-term precipitation variability in Morocco and the link to the large-scale circulation in recent and future climates. Meteorology and Atmospheric Physics, 83 (1-2), 67-88. doi:10.1007/s00703-002-0561-y

Kustas, W.P. and Rango, A., 1994. A simple energy budget algorithm for the snowmelt runoff model. Water Resources Research, 30, 1515-1527. doi:10.1029/ 94WR00152

Lang, H. and Braun, L., 1990. On the information content of air temperature in the context of snow melt estimation. IAHS Publication, 190, 347-354.

Li, L. and Pomeroy, J.W., 1997. Estimates of threshold wind speeds for snow transport using meteorological data. Journal of Applied Meteorology, 36 (3), 205-213. doi:10.1175/15200450(1997)036<0205:EOTWSF >2.0.CO;2

Li, X. and Williams, M.W., 2008. Snowmelt runoff modelling in an arid mountain watershed, Tarim Basin, China. Hydrological Processes, 22, 3931-3940. doi:10.1002/hyp. v22:19

Liston, G.E., et al., 2007. Instruments and methods simulating complex snow distributions in windy environments using snowTran-3D. Journal of Glaciology, 53, 241-256. doi:10.3189/172756507782202865

Liston, G.E. and Elder, K., 2006. A distributed snow-evolution modeling system (SnowModel). Journal of Hydrometeorology, 7 (6), 1259-1276. doi:10.1175/ JHM548.1

López-Moreno, J.I., et al., 2017. Different sensitivities of snowpacks to warming in Mediterranean climate mountain areas. Environmental Research Letters, 12 (7), 074006. doi:10.1088/1748-9326/aa70cb

López-Moreno, J.I., Goyette, S., and Beniston, M., 2009. Impact of climate change on snowpack in the pyrenees: horizontal spatial variability and vertical gradients. Journal of Hydrology, 374, 384-396. doi:10.1016/j. jhydrol.2009.06.049

MacDonell, S., et al., 2013. Meteorological drivers of ablation processes on a cold glacier in the semi-arid Andes of Chile. The Cryosphere, 7 (5), 1513. doi:10.5194/tc-71513-2013

Marchane, A., et al., 2015. Assessment of daily MODIS snow cover products to monitor snow cover dynamics over the Moroccan Atlas mountain range. Remote Sensing of Environment, 160, 72-86. doi:10.1016/j.rse.2015.01.002

Mazurkiewicz, A.B., Callery, D.G., and McDonnell, J.J., 2008. Assessing the controls of the snow energy balance and water available for runoff in a rain-on-snow environment. Journal of Hydrology, 354, 1-14. doi:10.1016/j. jhydrol.2007.12.027

Muñoz, E., et al., 2012. Gridded data for a hydrological model in a scarce-data basin. Water Management, 167 (5), 249-258.

Ohumura, A., 2001. Physical basis for the temperaturebased melt-index method. Journal of Applied Meteorology, 40, 753-761. doi:10.1175/1520-0450(2001) $040<0753:$ PBFTTB $>2.0 . C O ; 2$ 
Paton, F.L., Maier, H.R., and Dandy, G.C., 2013. Relative magnitudes of sources of uncertainty in assessing climate change impacts on water supply security for the southern Adelaide water supply system. Water Resources Research, 49 (3), 1643-1667. doi:10.1002/wrcr.20153

Pellicciotti, F., et al., 2005. An enhanced temperature-index glacier melt model including the shortwave radiation balance: development and testing for Haut Glacier d'Arolla, Switzerland. Journal of Glaciology, 51, 573-587. doi:10.3189/172756505781829124

Pellicciotti, F., et al., 2011. Transmission of solar radiation through clouds on melting glaciers: a comparison of parameterizations and their impact on melt modelling. Journal of Glaciology, 57, 367-381. doi:10.3189/002214311796406013

Pomeroy, J., et al., 1998. An evaluation of snow accumulation and ablation processes for land surface modelling. Hydrological Processes, 12 (15), 2339-2367. doi:10.1002/(SICI)1099-1085 (199812)12:15<2339::AID-HYP800>3.0.CO;2-L

Raleigh, M.S. and Lundquist, J.D., 2012. Comparing and combining SWE estimates from the SNOW-17 model using PRISM and SWE reconstruction. Water Resources Research, 48, 1. doi:10.1029/2011WR010542

Rango, A. and Martinec, J., 1995. Revisiting the degree-day method for snowmelt computations1. JAWRA Journal of the American Water Resources Association, 31 (4), 657669. doi:10.1111/jawr.1995.31.issue-4

Rasmussen, R., et al., 2012. How well are we measuring snow? Bulletin of the American Meteorological Society, 93, 811-829. doi:10.1175/BAMS-D-11-00052.1

Réveillet, M., et al., 2016. Which empirical model is best suited to simulate glacier mass balances? Journal of Glaciology, 63 (237), 39-54. doi:10.1017/jog.2016.110

Richard, C. and Gratton, D.J., 2001. The importance of the air temperature variable for the snowmelt runoff modelling using the SRM. Hydrological Processes, 15 (18), 33573370. doi:10.1002/(ISSN)1099-1085

Schneider, C., Kilian, R., and Glaser, M., 2007. Energy balance in the ablation zone during the summer season at the gran campo Nevado ice cap in the Southern Andes. Global and Planetary Change, 59, 175-188. doi:10.1016/j.gloplacha.2006.11.033

Schulz, O. and de Jong, C., 2004. Snowmelt and sublimation: filed experiments and modelling in the Hight Atlas
Mounatains of Morocco. Hydrology and Earth System Sciences, 8 (6), 1076-1086. doi:10.5194/hess-81076-2004

Singh, P. and Jain, S.K., 2003. Modelling of streamflow and its components for a large Himalayan basin with predominant snowmelt yields. Hydrological Sciences Journal, 48, 257-276. doi:10.1623/hysj.48.2.257.44693

Tarboton, D.G. and Luce, C.H., 1996. Utah energy balance snow accumulation and melt model (UEB). Logan, UT: Utah Water Research Laboratory Utah State University.

Tayal Senzeba, K., Bhadra, A., and Bandyopadhyay, A., 2015. Snowmelt runoff modelling in data scarce Nuranang catchment of eastern Himalayan region. Remote Sensing Applications: Society and Environment, 1, 20-35. doi:10.1016/j.rsase.2015.06.001

Verseghy, D.L., 1991. Class-A canadian land surface scheme for GCMS. I. Soil model. International Journal of Climatology, 11, 111-133. doi:10.1002/ joc.3370110202

Viviroli, D. and Weingartner, R., 2004. The hydrological significance of mountains: from regional to global scale. Hydrolgy \& Earth System Sciences, 8, 1016-1029.

Wagener, T., et al., 2003. Towards reduced uncertainty in conceptual rainfall-runoff modelling: dynamic identifiability analysis. Hydrological Processes, 17 (2), 455-476. doi:10.1002/hyp.1135

Willis, I.C., Arnold, N.S., and Brock, B.W., 2002. Effect of snowpack removal on energy balance, melt and runoff in a small supraglacial catchment. Hydrlogical Processes, 16, 2721-2749. doi:10.1002/hyp.1067

Willis, I.C., Sharp, M.J., and Richards, K.S., 1991. Studies of the water balance of Midtdalsbreen, Hardangerjökulen, Norway. Zeitschrift für Gletscherkunde und Glazialgeologie, 27, 117-138.

Würzer, S., et al., 2016. Influence of initial snowpack properties on runoff formation during rain-on-snow events. Journal of Hydrometeorology, 17 (6), 1801-1815. doi:10.1175/JHM-D-15-0181.1

Zuzel, J.F. and Cox, L.M., 1975. Relative importance of meteorological variables in snowmelt. Water Resources Research, 11, 174-176. doi:10.1029/WR011i001p00174 